\title{
Numerical simulation of the Filchner overflow
}

\author{
Article \\ Published Version
}

Wilchinsky, A. V. and Feltham, D. L. (2009) Numerical simulation of the Filchner overflow. Journal of Geophysical Research - Oceans, 114 (C12). C12012. ISSN 0148-0227 doi: https://doi.org/10.1029/2008JC005013 Available at https://centaur.reading.ac.uk/30573/

It is advisable to refer to the publisher's version if you intend to cite from the work. See Guidance on citing.

To link to this article DOI: http://dx.doi.org/10.1029/2008JC005013

Publisher: American Geophysical Union

All outputs in CentAUR are protected by Intellectual Property Rights law, including copyright law. Copyright and IPR is retained by the creators or other copyright holders. Terms and conditions for use of this material are defined in the End User Agreement.

\section{www.reading.ac.uk/centaur}

\section{CentAUR}

Central Archive at the University of Reading

Reading's research outputs online 


\title{
Numerical simulation of the Filchner overflow
}

\author{
Alexander V. Wilchinsky ${ }^{1}$ and Daniel L. Feltham ${ }^{1,2}$ \\ Received 11 July 2008; revised 29 July 2009; accepted 1 September 2009; published 9 December 2009.
}

[1] The plume of Ice Shelf Water (ISW) flowing into the Weddell Sea over the Filchner sill contributes to the formation of Antarctic Bottom Water. The Filchner overflow is simulated using a hydrostatic, primitive equation three-dimensional ocean model with a $0.5-2$ Sv ISW influx above the Filchner sill. The best fit to mooring temperature observations is found with influxes of 0.5 and $1 \mathrm{~Sv}$, below a previous estimate of $1.6 \pm 0.5 \mathrm{~Sv}$ based on sparse mooring velocities. The plume first moves north over the continental shelf, and then turns west, along slope of the continental shelf break where it breaks up into subplumes and domes, some of which then move downslope. Other subplumes run into the eastern submarine ridge and propagate along the ridge downslope in a chaotic manner. The next, western ridge is crossed by the plume through several paths. Despite a number of discrepancies with observational data, the model reproduces many attributes of the flow. In particular, we argue that the temporal variability shown by the observations can largely be attributed to the unstable structure of the flow, where the temperature fluctuations are determined by the motion of the domes past the moorings. Our sensitivity studies show that while thermobaricity plays a role, its effect is small for the flows considered. Smoothing the ridges out demonstrate that their presence strongly affects the plume shape around the ridges. An increase in the bottom drag or viscosity leads to slowing down, and hence thickening and widening of the plume.

Citation: Wilchinsky, A. V., and D. L. Feltham (2009), Numerical simulation of the Filchner overflow, J. Geophys. Res., 114, C12012, doi:10.1029/2008JC005013.

\section{Introduction}

[2] Antarctic Bottom Water (AABW) is one of the main constituents driving the global thermohaline circulation responsible for heat exchange between different regions of the Earth. AABW is in particular fed by Weddell Sea Bottom Water (WSBW). The Weddell Sea (Figure 1) is bounded from the west by the Antarctic Peninsula and from the south by the continental shelf break. The Ronne and Filchner Ice Shelf fronts, separated by Berkner Island, are 200-300 km south of the continental shelf break. Latent heat polynyas are present along the ice shelf front for most of the year due to offshore winds and tidal divergence [Foldvik et al., 2001; Renfrew et al., 2002]. The High Salinity Shelf Water(HSSW) generated through salt rejection during sea ice formation can directly contribute to WSBW by flowing down the continental slope [Gordon, 1998], or by mixing with offshelf water masses at the continental shelf, which allows it to overcome the dynamic barrier at the shelf break [Foster and Carmack, 1976]. HSSW can also penetrate into the cavity under the Filchner-Ronne Ice Shelf, convert to Ice Shelf Water (ISW) during interaction with the ice shelf [Foldvik and Gammelsrød, 1988], and subsequently leave the subice

\footnotetext{
${ }^{1}$ Centre for Polar Observation and Modeling, National Centre for Earth Observation, University College London, London, UK.

${ }^{2}$ British Antarctic Survey, Cambridge, UK.

Copyright 2009 by the American Geophysical Union. 0148-0227/09/2008JC005013
}

shelf cavity. Oceanographic data collected at hot water drilled access holes imply that HSSW formed just west of Berkner Island penetrates under the ice shelf, flows anticlockwise along the island's coast, and leaves the Filchner Depression over the Filchner sill [Nicholls et al., 2001]. Foldvik et al. [2004] analyzed mooring data and estimated the ISW outflow rate as $1.6 \pm 0.5 \mathrm{~Sv}$. The collected data also showed the potential temperature over the sill to be around $-2.05^{\circ} \mathrm{C}$, while the typical salinity of the ISW is around $34.6 \mathrm{psu}$ [Foldvik et al., 1985a]. Foldvik et al. [2004] used sparse mooring records to suggest three pathways for the ISW to flow into the Weddell Sea (Figure 2): two pathways along the continental slope with one, FO1, along the shelf break, and the other, FO2, further down the slope diverted there by a (western) ridge; and one pathway, FO3, down the slope along another prominent (eastern) ridge. The idealized dynamics of the last pathway was theoretically modeled by Darelius and Wåhlin [2007].

[3] The collected data of the Filchner overflow show rapid alterations between warm and cold water on a short timescale of several days. As the timescale of this variability is greater than a day, the variability cannot be directly attributed to tidal forcing. Flow energy variability of periods 3-60 days may, however, be caused by continental shelf waves, in particular due to variation in the along shore component of the wind stress [Middleton et al., 1982]. However, as the same period fluctuations are also observed for the temperature, the variability may rather be an intrinsic feature of the flow. Here our goal is to determine the main 


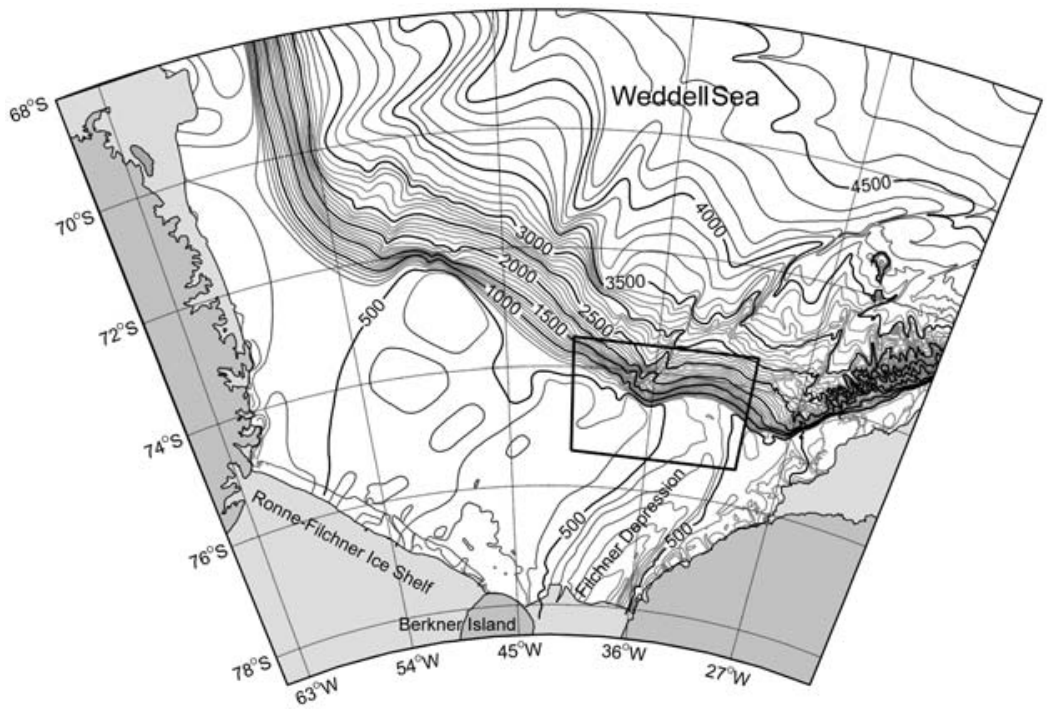

Figure 1. Bathymetric map of Weddell Sea with the area of interest in the box. Taken from Foldvik et al. [2004].

attributes of the ISW flow over the Filchner sill using a numerical oceanographic code POLCOMS (Proudman Oceanographic Laboratory Coastal-Ocean Modeling System). Our main interest lies in considering internal variability of the flow and the effect of ISW inflow rate; we also study the sensitivity of the model results to thermobaricity and the steepness of submarine ridges. We consider an idealized scenario where boundary forcing was held constant, and convective and diffusive exchanges of heat, moisture and momentum between the ocean and atmosphere were set to zero in order to focus solely on the internal variability of the flow. Tides are excluded and residual tidal currents are neglected since they are estimated by Makinson and Nicholls [1999] to be over ten times slower than the plume flows observed by Foldvik et al. [2004] and calculated by us. Our work compliments simultaneous studies by Matsumura and Hasumi [2008], Wang et al. [2009], and Darelius et al. [2009]. In section 2 we describe our model configuration. The mean characteristics of the plume for different inflow rates are discussed in section 3, while in section 4 we describe its instantaneous structure. Section 5 is devoted to sensitivity studies and our conclusions are summarized in section 6 .

\section{Model Configuration}

[4] POLCOMS is a hydrostatic, three-dimensional primitive equation ocean model initially developed for the simulation of shelf seas. Its detailed description is given by Holt and James [1999, 2001]. POLCOMS has proved to be effective at sub-Rossby radius resolutions [Holt and Proctor, 2008], which has proved useful in modeling flows steered by topography not identified with other numerical models, e.g. a narrow coastal current generated by a density source in a polynya [Wilchinsky and Feltham, 2008]. Such topographically steered currents are a feature of the flow simulated in this paper. The model is run on an Arakawa B grid, uses a terrain following sigma coordinate transformation, and the Piecewise Parabolic Method advection scheme to minimize numerical diffusion [James, 1996]. Ocean density is calculated using the UNESCO equation of state [Mellor, 1991]. The upper ocean surface is a free surface,

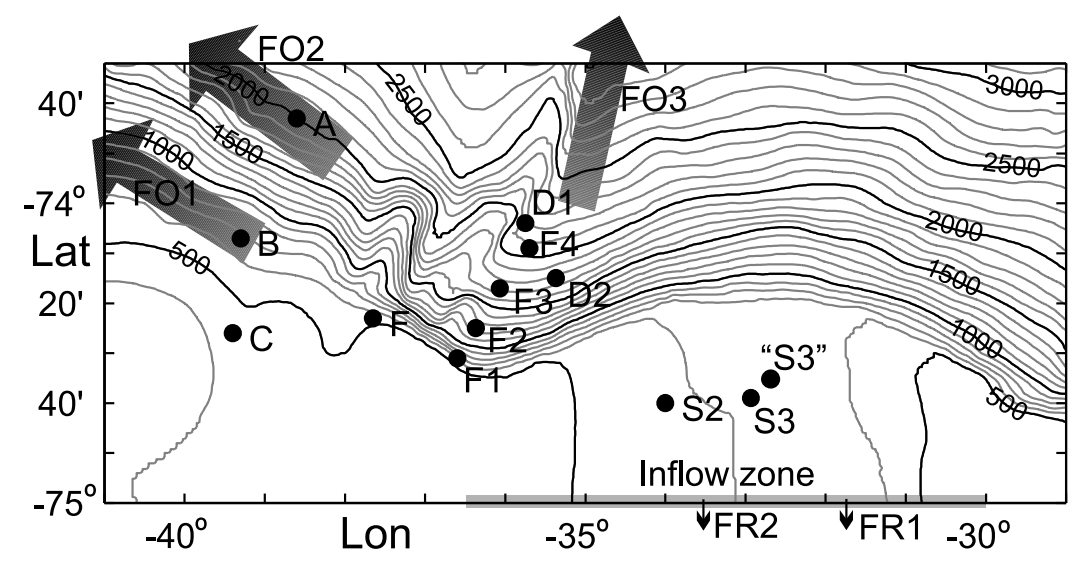

Figure 2. Bathymetry of the simulation domain. The dots are mooring positions described by Foldvik et al. [2004], who also proposed the three plume pathways FO1-FO3 shown here by wide gray arrows. 
and at the ocean bottom a quadratic drag law is used with a drag coefficient taken to be 0.004 as proposed by measurements from the Faeroe Bank overflow [Mauritzen et al., 2005]. Small scale disturbances are smoothed out by a gridsplitting suppression algorithm [Killworth et al., 1991], and we put the horizontal viscosity and diffusivities to zero. The grid-splitting suppression, however, gives rise to some degree of numerical mixing. We found that a linear Richardson mixing scheme used in POLCOMS v6.2.2 performed better when compared to mooring temperature histograms given by Foldvik et al. [2004] than the Mellor-Yamada-Galperin level 2.5 turbulence closure scheme with an algebraic mixing length also available in the code. Therefore it was decided to use the Richardson mixing scheme. The vertical eddy viscosity and diffusivity, $A_{z}$, is taken to depend linearly on the Richardson number as

$$
\begin{aligned}
& A_{z}=\frac{1}{5} \max \left[10^{-5},\left(u_{*} l+0.002\right) \frac{0.23-R i}{0.23}\right] \text { for } R i \geq 0 \\
& A_{z}=\frac{1}{5} 10^{-5} \quad \text { for } \quad R i<0
\end{aligned}
$$

where the coefficient $1 / 5$ is inserted by us as it improves the model results relative to observations as has been found during sensitivity studies, the constant $0.002 \mathrm{~m}^{2} \mathrm{~s}^{-1}$ models mixing due to background wave activity, $10^{-5} \mathrm{~m}^{2} \mathrm{~s}^{-1}$ is the minimum eddy diffusivity, the mixing length $l=0.05 h$ ( $h$ is the depth), the friction velocity $u_{*}$ is determined through the bottom drag, and the Richardson number is

$$
R i=\frac{\partial b}{\partial z} \frac{1}{\left(\frac{\partial u}{\partial z}\right)^{2}+\left(\frac{\partial v}{\partial z}\right)^{2}}
$$

with $u, v$ and $b$ being horizontal velocities and buoyancy. The buoyancy is defined through the in situ density $\rho$ as $b=$ $g\left(\rho_{0}-0.004564 z-\rho\right) / \rho_{0}$, where $(-z)$ is the depth, $\rho_{0}=$ $1027 \mathrm{~kg} \mathrm{~m}^{-3}$ is the reference density at the surface, while the second term describes the effect of compression on the reference density at depth. The eddy viscosity is estimated to be of order $0.05 \mathrm{~m}^{2} \mathrm{~s}^{-1}$ near the bottom of the plume over the continental shelf, which in turn determines the Ekman layer depth there to be around $30 \mathrm{~m}$. The eddy viscosity can reach $0.3 \mathrm{~m}^{2} \mathrm{~s}^{-1}$ between the continental slope and the eastern ridge determining an Ekman layer depth of $70 \mathrm{~m}$. A typical eddy viscosity west of the western ridge is estimated to be $0.1 \mathrm{~m}^{2} \mathrm{~s}^{-1}$, determining an Ekman layer depth of $40 \mathrm{~m}$.

[5] Because turbulent closures usually treat unstably stratified water columns inadequately [e.g., Deleersnijder and Luyten, 1994], a convective adjustment scheme is employed in POLCOMS: where stratification is unstable the salinity and temperature are replaced by their mean values in an upper layer whose thickness is the minimum thickness that provides a stable stratification after the adjustment. Due to the stable stratification of the water, the convective adjustment is not expected to play a significant role here.

[6] The model is run in spherical coordinates on a numerical grid with a horizontal resolution of $1.5^{\prime}$ longitude and $0.4^{\prime}$ latitude, which is approximately $750 \mathrm{~m}$ in both directions. The calculation domain covers the area between $-41^{\circ}$ and $-29^{\circ}$ longitude and $-75^{\circ}$ and $-73^{\circ} 28^{\prime}$ latitude. We used a $1^{\prime}$ resolution bathymetry map from GEBCO (General Bathymetric Chart of the Oceans) which is maintained and updated by the British Oceanographic Data Centre (www.bodc.ac.uk). The bathymetry map interpolated at our model's grid points is presented in Figure 2. Vertically 120 uniform layers are used in sigma coordinates, which ensures a vertical resolution of around $4.2 \mathrm{~m}$ at $500 \mathrm{~m}$ depth and $16.7 \mathrm{~m}$ at $2000 \mathrm{~m}$ depth (the lowest grid points are positioned half of the resolution length above the bottom). This vertical resolution is still smaller than the submarine ridge height of more than $100 \mathrm{~m}$. The Ekman layer is covered by around 7 sigma layers over the continental shelf, and 3-5 layers west of the western ridge. We performed POLCOMS simulations using a nonuniform sigma grid such that a near-bottom vertical resolution of $4.2 \mathrm{~m}$ was used throughout the model domain, but abandoned this approach since the simulations were significantly worse (compared to observations) than those obtained using the default configuration of a uniform sigma vertical grid.

[7] The barotropic and baroclinic time steps were taken as $4 \mathrm{~s}$ and $200 \mathrm{~s}$ respectively in order to avoid numerical instability. Boundary forcing was held constant, and convective and diffusive exchanges of heat, moisture and momentum between the ocean and atmosphere were set to zero in order to focus solely on the internal variability of the flow. In particular the effect of tides and the Antarctic coastal current [Deacon, 1937; Gill, 1973] that flows along the continental shelf break from the east are disregarded. While East of $27^{\circ}$ longitude the current is described by a pronounced V-shaped region of cold and low salinity water, at this location it splits into two branches: one along the continental shelf break, while the other along the coastline toward the Filchner Ice shelf [Foster and Carmack, 1976; Foldvik et al., 1985b]. The former branch, which enters our domain, is the weaker and while the salinity anomaly is still present, the $\mathrm{V}$ shape is much less pronounced and is neglected here.

[8] The boundary conditions at all the boundaries (except for the inflowing ISW area) are taken as linear approximations to the potential temperature and salinity profiles at the continental slope obtained during the Norwegian Antarctic Expedition in 1990 [Foldvik et al., 2004] when the ISW plume contribution is disregarded (Figure 3). In order to allow the fluid to leave the domain, we assumed that the velocities at boundaries everywhere apart from the inflow region are equal to the velocities at the previous time step at the adjacent internal nodes. This complements a radiation boundary condition for the upper surface adopted in POLCOMS that allows surface waves to leave the domain in order to prevent their radiation from the boundaries that could occur when the water depth there is fixed.

[9] The inflowing ISW has a potential temperature of $-2.05^{\circ} \mathrm{C}$ and salinity of $34.6 \mathrm{psu}$. With a reduced gravity of order $5 \cdot 10^{-4} \mathrm{~m} \mathrm{~s}^{-2}$, a velocity of $0.05 \mathrm{~m} \mathrm{~s}^{-1}$ and with the Coriolis parameter equal to $1.4 \cdot 10^{-4} \mathrm{~s}^{-1}$, geostrophic equilibrium would require the plume's aspect ratio to be $10^{-2}$. For a $200 \mathrm{~m}$ deep plume this would determine a plume width of $20 \mathrm{~km}$ and an inflow rate of $0.1 \mathrm{~Sv}$, which is an order of magnitude less than estimated from observations [Foldvik et $a l ., 2004]$, so that we conclude that the incoming flow is not geostrophic. Therefore we consider the plume to enter the 


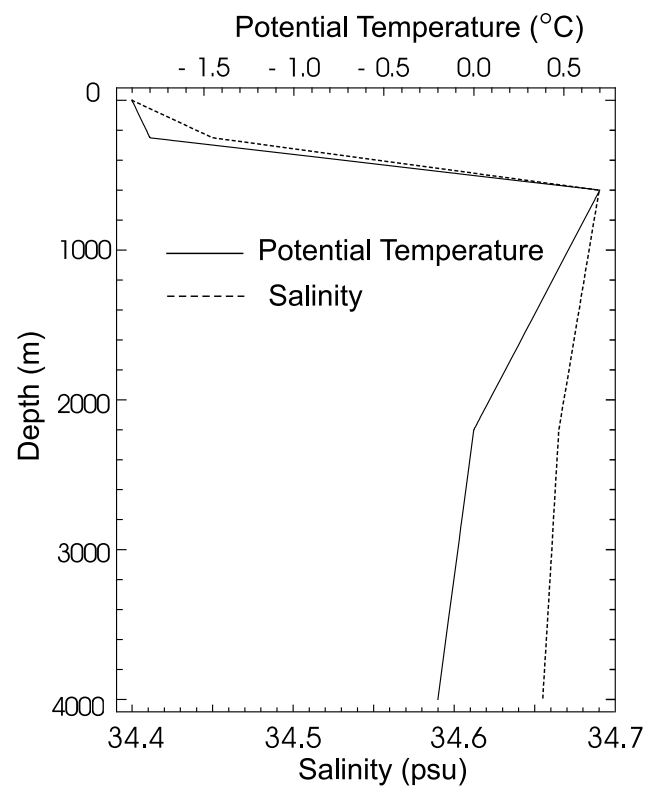

Figure 3. Adopted potential temperature and salinity distributions at the boundaries, as well as for the initial state.

domain from the south between the bathymetry contours of 410 meters, namely, approximately between $-35.5^{\circ}$ and $-30^{\circ}$ longitude for our runs with an inflow rate of $1 \mathrm{~Sv}$ or more when we consider a symmetric parabolic upper surface profile (Figure 4). The plume transport in the $\mathrm{S}$ section was estimated by Foldvik et al. [2004] as $1.7 \pm 0.5 \mathrm{~Sv}$ and in the F section as $1.5 \pm 0.3 \mathrm{~Sv}$. Since only a limited number of moorings were used in the $\mathrm{S}$ section, the estimates may have even higher uncertainty. In particular, in the S section the northern velocity of around $7 \mathrm{~cm} \mathrm{~s}^{-1}$ measured at mooring S3 was assumed to extend for more than $50 \mathrm{~km}$ east, while the northern velocity at mooring "S3" positioned just 4 " latitude $(7.4 \mathrm{~km})$ north and $17^{\prime \prime}$ longitude $(8.5 \mathrm{~km})$ east of S3 was effectively zero. Since the S section width is around $200 \mathrm{~km}$, this may reduce the estimate. Therefore, here we will consider four runs we will call R1 - R4 with different inflow rates of $0.52 \mathrm{~Sv}, 1.05 \mathrm{~Sv}, 1.56 \mathrm{~Sv}$ and $2.1 \mathrm{~Sv}$. For the runs with the inflow rate higher than $1 \mathrm{~Sv}$ we increase the incoming speed of the plume which is directed north, while keeping its shape constant, as we do not expect the plume surface to rise significantly over the height of the cavity. For our run with $0.52 \mathrm{~Sv}$ inflow rate we chose an ISW profile leaning to the western side with reduced inflow area so that the speed does not reduce too much (Figure 4). The corresponding mean inflow speeds during runs R1-R4 were $3.1 \mathrm{~cm} \mathrm{~s}^{-1}, 4 \mathrm{~cm} \mathrm{~s}^{-1}$, $6 \mathrm{~cm} \mathrm{~s}^{-1}$ and $8 \mathrm{~cm} \mathrm{~s}^{-1}$ respectively. The mean northward velocities at moorings FR1 and FR2 positioned $1^{\prime}$ and $2^{\prime}$ just south of the southern domain boundary at longitudes shown in Figure 2 vary between $7 \mathrm{~cm} \mathrm{~s}^{-1}$ and $5.2 \mathrm{~cm} \mathrm{~s}^{-1}$ below $232 \mathrm{mab}$ (meters above bottom) and are around $0 \mathrm{~cm} \mathrm{~s}^{-1}$ below 126 mab respectively with standard deviation of order $7 \mathrm{~cm} \mathrm{~s}^{-1}$ [Foldvik et al., 2004]. The average between them would be $3 \mathrm{~cm} \mathrm{~s}^{-1}$.

[10] We ran POLCOMS on 118 processors with rectangular domain decomposition on the UK supercomputer cluster HECToR (High-End Computing Terascale Resource) based on the CRAY XT4. Our simulation lasts 150 model days. It takes less than 30 days for the plume to cover the

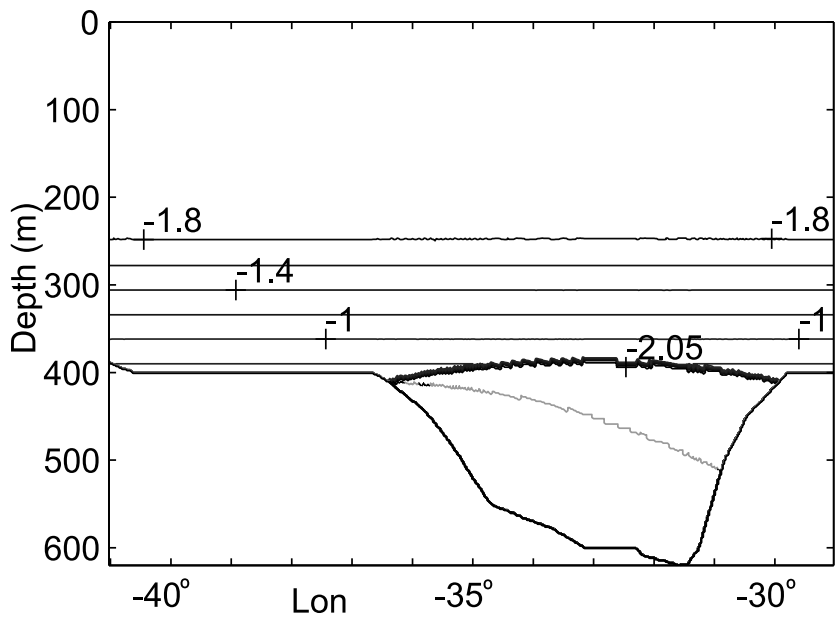

Figure 4. Potential temperature distribution at the vertical domain boundary along $-75^{\circ}$ latitude. The inflowing ISW plume has a parabolic profile for runs $\mathrm{R} 2-\mathrm{R} 4$ and a potential temperature of $-2.05^{\circ} \mathrm{C}$. The gray line shows the adopted plume profile for run $\mathrm{R} 1$.

computational domain for the two weaker influx runs R1 and $\mathrm{R} 2$, and less than 40 days for the two stronger influx runs R3 and R4. We perform our statistical data analyses for 100 days after that. We will present calculation results at mooring positions described by Foldvik et al. [2004]. Multiple moorings B1, B2 and B3 are situated close to each other, and therefore will be described here by one position denoted B. The mooring locations we use are given in Table 1. The corresponding depths calculated using our bathymetry data are slightly different from those given by Foldvik et al. [2004]. Below, by referring to any measurement or observational data, we refer to the data published by Foldvik et al. [2004].

\section{Variation of the Inflow Rate}

\subsection{Mean Flow Characteristics}

[11] We define the plume depth as the layer where the potential temperature is less than or equal to $-1^{\circ} \mathrm{C}$. The value of $-1^{\circ} \mathrm{C}$, although somewhat arbitrary, was chosen because, as will be seen next from the mooring potential temperature histograms, the frequency peaks that we associate with the plume are situated just left (on the colder side) of $-1^{\circ} \mathrm{C}$. Where the ambient temperature is less than $-1^{\circ} \mathrm{C}$,

Table 1. Positions of the Moorings and the Ocean Depth

\begin{tabular}{llcc}
\hline Name & Latitude & Longitude & Depth (m) \\
\hline A & $-73^{\circ} 43^{\prime}$ & $-38^{\circ} 36^{\prime}$ & 1996 \\
B & $-74^{\circ} 07^{\prime}$ & $-39^{\circ} 18^{\prime}$ & 677 \\
C & $-74^{\circ} 26^{\prime}$ & $-39^{\circ} 24^{\prime}$ & 443 \\
D1 & $-74^{\circ} 04^{\prime}$ & $-35^{\circ} 45^{\prime}$ & 2155 \\
D2 & $-74^{\circ} 15^{\prime}$ & $-35^{\circ} 22^{\prime}$ & 1771 \\
F & $-74^{\circ} 23^{\prime}$ & $-37^{\circ} 39^{\prime}$ & 564 \\
F1 & $-74^{\circ} 31^{\prime}$ & $-36^{\circ} 36^{\prime}$ & 602 \\
F2 & $-74^{\circ} 25^{\prime}$ & $-36^{\circ} 22^{\prime}$ & 1232 \\
F3 & $-74^{\circ} 17^{\prime}$ & $-36^{\circ} 04^{\prime}$ & 1724 \\
F4 & $-74^{\circ} 09^{\prime}$ & $-35^{\circ} 42^{\prime}$ & 2056 \\
S2 & $-74^{\circ} 40^{\prime}$ & $-34^{\circ} 00^{\prime}$ & 578 \\
S3 & $-74^{\circ} 39^{\prime}$ & $-32^{\circ} 56^{\prime}$ & 616 \\
\hline
\end{tabular}




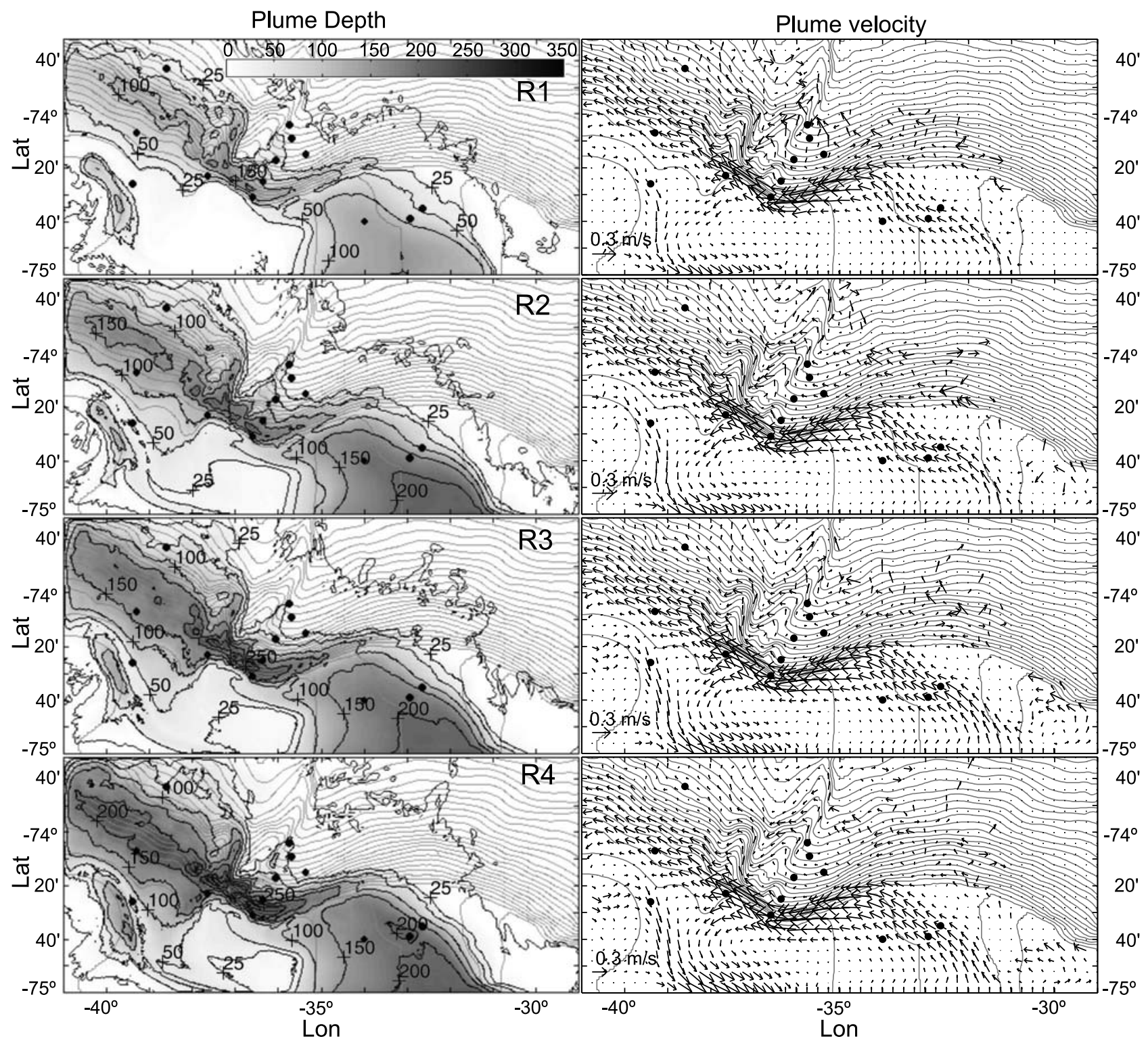

Figure 5. (left) The plume depth averaged in time. The contour lines are every $50 \mathrm{~m}$. A $25 \mathrm{~m}$ contour line is added to show the plume extent. (right) Mean plume velocities (averaged with regard to depth and time). The velocity scale increases with the inflow rate.

the top of the plume is identified by the steep temperature gradient there. It can be seen that in terms of mean depth and velocities, shown in Figure 5, the different run results differ mainly quantitatively while producing a qualitatively similar picture. After entering the domain the plume flow readjusts itself around halfway to the $\mathrm{S}$ section. It turns northwest under the action of the Coriolis force constrained by the bathymetry, the flow band narrows and the plume speeds up. If we denote the reduced gravity by $g^{\prime}=g(\rho-$ $\left.\rho_{a}\right) / \rho_{0}$, where $\rho_{a}$ is the initial density of the ambient water at the depth, and $\rho_{0}=1027 \mathrm{~kg} \mathrm{~m}^{-3}$, then the typical value for the reduced gravity in the $\mathrm{S}$ section is $5 \cdot 10^{-4} \mathrm{~m} \mathrm{~s}^{-2}$. Between the inflow region and the continental break the thickness changes by around $h=100 \mathrm{~m}$, and this gives the gravity-inertia speed of the plume $V=\left(g^{\prime} h\right)^{1 / 2} \approx 0.2 \mathrm{~m} \mathrm{~s}^{-1}$ that compares well with the simulated speed at S3 (Table 3 showing simulation results at moorings for R2), indicating that the plume is primarily propagating as a gravity current, which leads to its acceleration and thinning as it approaches the continental shelf break. The plume is more than $100 \mathrm{~km}$ wide before it reaches the steep continental slope where the across-slope pressure gradient increases and the Coriolis force drives the flow along slope. This is accompanied by narrowing of the plume width down to $30 \mathrm{~km}$, increasing its depth, and an increase in the speed to balance the increase in the across-slope pressure gradient. For all runs except R1 the plume front (associated with the $25 \mathrm{~m}$ depth contour) upstream of the eastern ridge is close to D2. This is not the case for R1 because its mean plume depth is comparable with $25 \mathrm{~m}$, so that the $25 \mathrm{~m}$ contour line is more sensitive to the plume shape. Since the plume is narrow around D2, most of the plume can squeeze into the corridor between the continental shelf break and the southern end of the eastern ridge. The flow along the eastern side of the eastern ridge is 


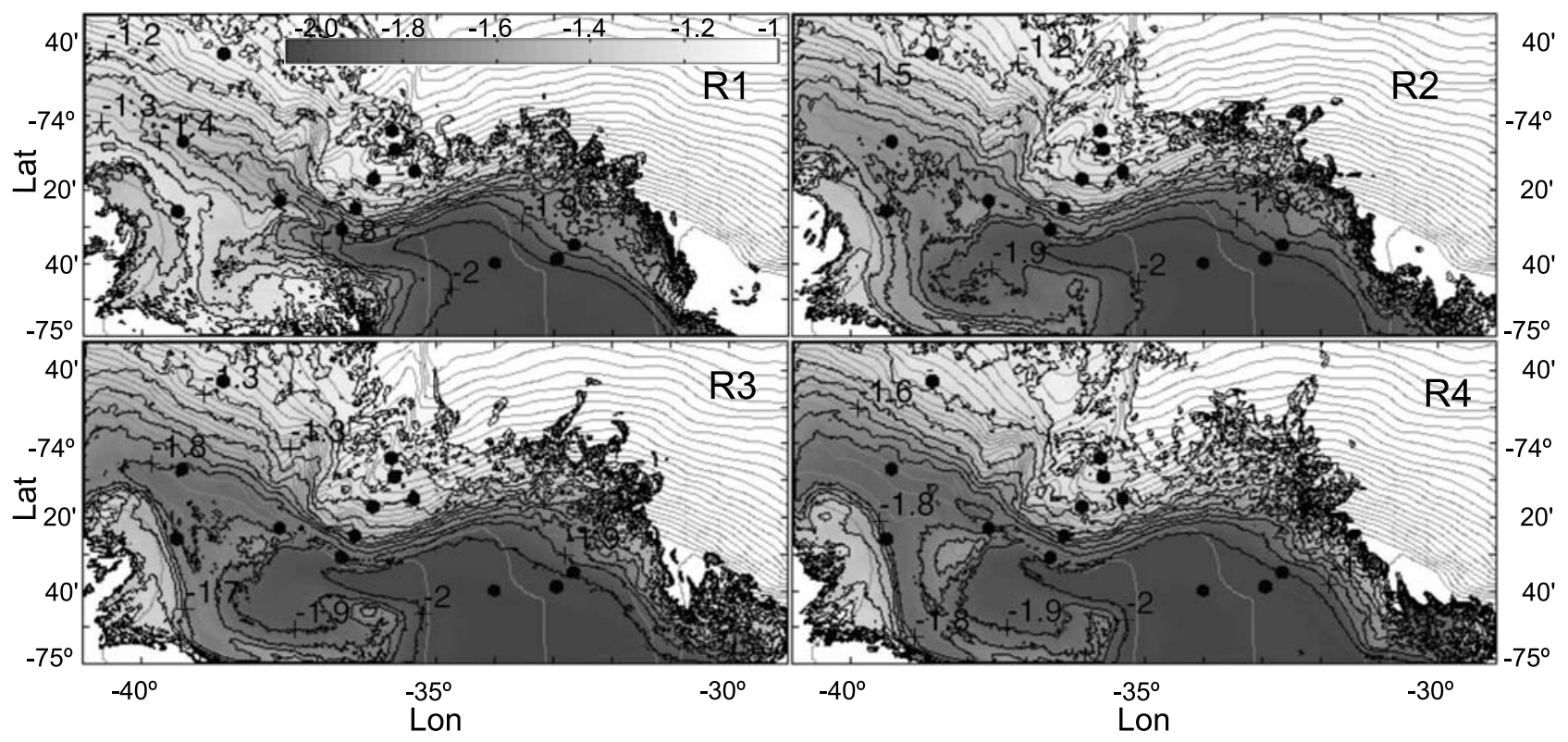

Figure 6. The mean potential temperature averaged with regard to depth and time for runs R1-R4.

fed primarily by breakaway subplumes discussed later. The next, western ridge originates at the shelf break so that there is less space for the plume to propagate along slope and the flow is partly diverted downslope along the ridge and encompasses it from the north. A canyon opposite to the ridge diverts part of the flow back south which then moves anticyclonically due to the Coriolis force. Beyond the ridge the mean flow mainly follows the isobaths, and, as the bottom slope decreases, the plume widens and slows in order to balance the reduced across-slope pressure gradient.

[12] Generally, as the inflow rate of ISW increases, the depth and speed of the plume also increases, as could be expected from mass conservation. Higher inflow rates also imply lower potential temperatures (Figure 6) west of the western ridge due to higher fractions of unmixed ISW. Plotting mean potential vorticity (not shown) shows that dissipation and mixing is not important only over the continental shelf, and the presence of the continental slope induces anticyclonic rotation through shear. Our calculations of transport of WSBW (Table 2) shows that generally WSBW transport across isobaths does not change monotonically either with water column depth or with the inflow rate. The latter naturally affects the WSBW transport across the western domain boundary since it is crossed by the plume.

\subsection{Potential Temperature Histograms}

[13] In Figure 7 we show temperature histograms for runs R1-R4, which can be compared to those given by observations presented in Figure 3 of Foldvik et al. [2004]. The measurement data for F1, F2 and F3 show a peak of frequency at around $-1.9^{\circ} \mathrm{C}$ describing a frequent presence of ISW with a sharp lower cutoff at $-2^{\circ} \mathrm{C}$ and a more gentle decrease in frequency toward the ambient temperature. A similar behavior is observed at mooring $\mathrm{C}$, where there is little presence of water below $-1.9^{\circ} \mathrm{C}$ and the peak may be attributed to HSSW formation over the continental shelf. In our calculations for the deeper moorings F2 and F3 we see similar peaks, but describing ISW several tenths of a degree warmer. For mooring F1 the model shows an increasingly frequent presence of ISW as the inflow rate increases, with the best match to observations given by the lowest inflow rate, which, however, still produces too frequent a presence of ISW. When we used a narrower ISW inflow profile that was $500 \mathrm{~m}$ deep with an inflow rate similar to run R1 presented here, the plume quickly broke up into eddies and

Table 2. WSBW Transport Across Isobaths of 1500, 2000, and $2500 \mathrm{~m}$ in the Area Lying Beyond 20 Grid Points From All the Boundaries to Exclude Boundary Effects ${ }^{\mathrm{a}}$

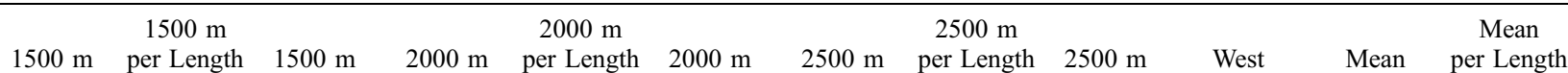

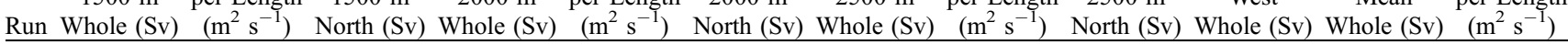

\begin{tabular}{|c|c|c|c|c|c|c|c|c|c|c|c|c|}
\hline $\mathrm{R} 1$ & 0.35 & 0.74 & 0.03 & 0.29 & 0.67 & 0.11 & 0.19 & 0.84 & 0.29 & 0.42 & 0.26 & 0.64 \\
\hline $\mathrm{R} 2$ & 0.4 & 0.83 & 0.06 & 0.32 & 0.76 & 0.22 & 0.16 & 0.72 & 0.44 & 0.77 & 0.28 & 0.69 \\
\hline R3 & 0.5 & 1.04 & 0.06 & 0.3 & 0.7 & 0.28 & 0.21 & 0.93 & 0.42 & 1.1 & 0.3 & 0.75 \\
\hline R4 & 0.39 & 1.04 & 0.17 & 0.24 & 0.57 & 0.29 & 0.12 & 0.53 & 0.47 & 1.5 & 0.25 & 0.6 \\
\hline NT & 0.4 & 0.84 & 0.02 & 0.3 & 0.71 & 0.19 & 0.07 & 0.3 & 0.38 & 0.83 & 0.26 & 0.63 \\
\hline SB & 0.36 & 0.79 & 0.23 & 0.27 & 0.69 & 0.13 & 0.18 & 0.6 & 0.15 & 0.84 & 0.24 & 0.6 \\
\hline
\end{tabular}

${ }^{\mathrm{a}} \mathrm{WSBW}$ is defined by potential temperatures less than or equal to $-0.7^{\circ} \mathrm{C}$. As the isobath lengths differ we give the WSBW transport across the whole length of the isobaths ("Whole"), per unit length of isobath ("Per Length"), and through the northern domain edge west of where the isobaths intersect the northern boundary ("North"). "West" shows the transport across the western boundary and "Mean" gives the values averaged for the eleven $100 \mathrm{~m}$ distant isobaths between $1500 \mathrm{~m}$ and $2500 \mathrm{~m}$. 


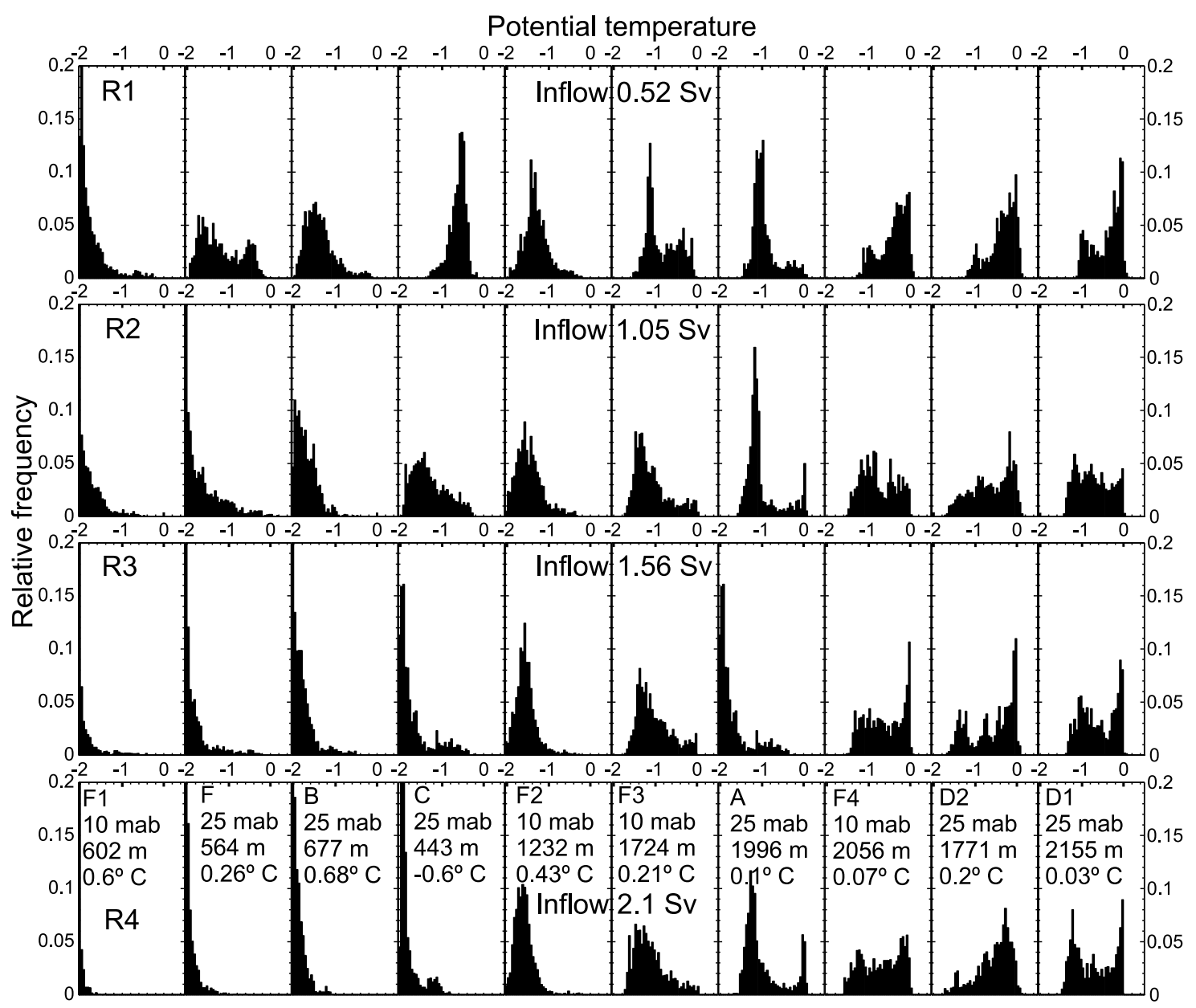

Figure 7. Histogram of the frequency of potential temperature at some of the bottom moorings for runs $\mathrm{R} 1-\mathrm{R} 4$. The temperature interval is $0.05^{\circ} \mathrm{C}$. The distance from the bottom, the water column depth, and the mooring ambient temperature are also shown.

achieved a better match with the histograms at moorings F1, $\mathrm{F}$ and $\mathrm{B}$ (not shown). This was due to a high proportion of ISW trapped in the eddies.

[14] As mooring $\mathrm{C}$ is situated further away, onshore, from the continental shelf break, the histograms show a more pronounced difference between the runs: in $\mathrm{R} 1$ the reverting flow of the plume is the weakest, so that it does not reach the mooring site, while in R3 and R4 ISW dominates the measurements. Interestingly, R2 with a moderate reverting flow provides a rather good fit to the observations and we conclude that mooring $\mathrm{C}$ measurements may be explained not only by HSSW formation but also by the plume reaching this position.

[15] From Figure 5 it can be seen that mooring $F$ is situated right at the edge of the plume, so that observations show an arbitrary intermittency between the water masses with potential temperature ranging between those of the plume at this location and the ambient. Mooring $\mathrm{B}$ is submerged by the plume and observations describe a rather symmetrical and bell-shaped histogram which shows a rather uniform presence of different water origins as well as strong mixing. These mooring histograms are best described by R1, while the other runs show a dominating presence of much less diluted ISW. Although generally the simulated flow is unstable, higher inflow rates ensure a steady layer of ISW near the bottom where the measurements were taken.

[16] Mooring A is situated near the north edge of the plume, and runs R1, R2 and R4 show the plume reaches this location in a very well mixed state (run R3 shows a strong presence of ISW), which supports the conclusions of Foldvik et al. [2004] describing the FO2 path going through mooring $\mathrm{A}$ as being a well-mixed water mass. The observations show that at F4 and D2 the main water mass present is the ambient. As the front of the plume is situated the farthest from F4 in R1, it is the best fit for F4, while the other runs describe a more frequent presence of mixed ISW. At D2 all the runs produce a qualitatively similar fit.

[17] Observations at mooring D1 are described in more detail by Darelius and Wählin [2007] and interpreted as "a pulsating flow, where quiescent periods, during which the mooring is submerged in warm WDW [Weddell Deep Water], are interrupted by dynamic episodes or pulses of cold ISW or ISW/WDW mixture flowing by the mooring at high speeds (up to $1 \mathrm{~m} / \mathrm{s}$ )". Apart from the higher minimum temperatures describing mixed ISW, the best qualitative histogram fit is given by $\mathrm{R} 2$, while the other runs describe a more frequent presence of the ambient water and weaker mixing of the ISW. 
Table 3. Mean Simulated Fields and Their Standard Deviations at the Mooring Positions for Run R2 ${ }^{\mathrm{a}}$

\begin{tabular}{|c|c|c|c|c|c|c|c|c|c|}
\hline Name & $\mathrm{mab}(\mathrm{m})$ & $u\left(\mathrm{~cm} \mathrm{~s}^{-1}\right)$ & $\sigma_{u}\left(\mathrm{~cm} \mathrm{~s}^{-1}\right)$ & $v\left(\mathrm{~cm} \mathrm{~s}^{-1}\right)$ & $\sigma_{v}\left(\mathrm{~cm} \mathrm{~s}^{-1}\right)$ & $\theta\left({ }^{\circ} \mathrm{C}\right)$ & $\sigma_{\theta}\left({ }^{\circ} \mathrm{C}\right)$ & $s(\mathrm{psu})$ & $\sigma_{s}\left(10^{-2} \mathrm{psu}\right)$ \\
\hline $\mathrm{A}$ & 25 & -3 & 8.1 & 1.9 & 6.7 & -0.99 & 0.42 & 34.648 & 0.829 \\
\hline B & 25 & -11.6 & 4.3 & 8 & 4.5 & -1.71 & 0.25 & 34.612 & 0.796 \\
\hline $\mathrm{C}$ & 25 & 8 & 4.2 & -12.2 & 4.1 & -1.3 & 0.41 & 34.601 & 0.86313 \\
\hline D1 & 25 & 0.38 & 8.3 & 7.0 & 6.8 & -0.72 & 0.4 & 34.653 & 0.783 \\
\hline D2 & 25 & -4.7 & 9.0 & -1.7 & 7.6 & -0.63 & 0.47 & 34.652 & 1.124 \\
\hline $\mathrm{F}$ & 25 & -22 & 3.7 & 3.9 & 2.8 & -1.63 & 0.45 & 34.606 & 1.132 \\
\hline $\mathrm{F} 1$ & 10 & -31.5 & 3.9 & 32.0 & 3.38 & -1.86 & 0.28 & 34.604 & 0.777 \\
\hline $\mathrm{F} 1$ & 56 & -40 & 4.9 & 32 & 4.8 & -1.76 & 0.45 & 34.607 & 1.14 \\
\hline $\mathrm{F} 1$ & 207 & -33.6 & 5.9 & 17 & 5 & -0.85 & 0.34 & 34.541 & 2.872 \\
\hline $\mathrm{F} 2$ & 10 & -9.6 & 9.3 & 5.4 & 7.1 & -1.47 & 0.32 & 34.627 & 1.116 \\
\hline F3 & 10 & -4.43 & 8.8 & -0.8 & 8.3 & -1.09 & 0.41 & 34.642 & 1.08 \\
\hline F3 & 56 & -3 & 9.4 & -1.9 & 8.8 & -0.74 & 0.55 & 34.648 & 1.213 \\
\hline F4 & 10 & -3.6 & 7.3 & 1.6 & 6.3 & -0.76 & 0.4 & 34.652 & 0.898 \\
\hline $\mathrm{S} 2$ & 25 & -6 & 2.6 & 6.2 & 2 & -2.05 & 0 & 34.6 & 0.85 \\
\hline $\mathrm{S} 2$ & 100 & -6.2 & 2.8 & 5.9 & 2.07 & -2.05 & 0 & 34.601 & 0.085 \\
\hline S3 & 25 & -16.8 & 4 & 7.4 & 3.4 & -1.95 & 0.4 & 34.604 & 1.181 \\
\hline $\mathrm{S} 3$ & 100 & -17.3 & 4.2 & 6.2 & 3.8 & -1.79 & 0.66 & 34.605 & 1.255 \\
\hline
\end{tabular}

${ }^{\text {a}}$ Where $u$ and $v$ are the eastward and northward velocities, respectively; $\theta$ is the potential temperature; and $s$ is the salinity.

[18] Taken as a whole, we conclude that the weakest inflow rate run, $\mathrm{R} 1$, produces a better fit to the histograms, especially for moorings $\mathrm{F}$ and $\mathrm{B}$ where the other runs describe insufficient mixing. R2, however, is better for moorings $\mathrm{C}$ and D1. R3 and R4 describe a strong presence of ISW at F1, F, $\mathrm{B}$ and $\mathrm{C}$.

\subsection{ISW Transport}

[19] Our comparison of the potential temperature histograms showed that there is no single ISW transport rate that would determine the best fit for all histograms at once. It should however be noted that the measurements for the F section were made in 1998, for mooring B in 1968, FR1 and FR2 in 1995, and C, F, and A in 1977. As was shown by Foldvik et al. [2004], seasonal variability changes the northward velocity at FR 1 from around $2 \mathrm{~cm} \mathrm{~s}^{-1}$ to over $10 \mathrm{~cm} \mathrm{~s}^{-1}$. Similarly interannual variability can also be significant. In particular, Nicholls and Østerhus [2004] interpreted measurements under the Ronne Ice Shelf southwest of the Berkner Island and found that the ventilation speed changed from $45 \mathrm{~cm} \mathrm{~s}^{-1}$ in 1999 to less than $20 \mathrm{~cm} \mathrm{~s}^{-1}$ in 2001 . Therefore it may be impossible to fit the mooring data collected during different years to simulations with only one ISW inflow rate. Based on our model results we expect that the ISW inflow rate was lower in 1968 and 1977 (moorings $\mathrm{F}$ and B) than in 1998 (F section).

[20] The fact that the run with the best overall fit to the temperature histograms, R1 (0.52 Sv), has a much lower ISW influx rate than the estimate found by Foldvik et al. [2004] (1.6 $\pm 0.5 \mathrm{~Sv})$ may be due to the idealized nature of the model, excluded interannual variability of the observational transport estimate as discussed above, and/or overestimation of the influx rate from the sparse observations. For example, it is possible that variability in the external forcing, not included in our simulations, might cause on average greater intermittency and mixing at moorings F1, F, $\mathrm{B}$ and $\mathrm{C}$. At the same time, the high degree of uncertainty in estimating the ISW transport by interpreting sparse mooring data is indicated by the earlier estimate of $0.7 \mathrm{~Sv}$ [Foldvik et al., 1985a] using data from only one mooring, S2. The $\mathrm{S}$ section shown later in Figure 16 was used by Foldvik et al. [2004] to obtain an estimate for the ISW transport there as $1.7 \pm 0.5 \mathrm{~Sv}$ in 1985 based on data from two mooring positions at different depths: S2 and S3. ISW in the S section is less mixed than in the F section, therefore errors relating to identification of ISW contribution are effectively removed in the $\mathrm{S}$ section. Our R2 run that uses a $1.05 \mathrm{~Sv}$ ISW inflow rate produces northward velocities at moorings S2 (25 mab and $100 \mathrm{mab}$ ) and S3 (25 mab) (Table 3) which are somewhat higher than those used by Foldvik et al. [2004] to generate the $1.7 \pm 0.5 \mathrm{~Sv}$ estimate. While the northward velocity at moorings S3 (100 mab) is only $0.1 \mathrm{~cm} \mathrm{~s}^{-1}(2 \%)$ lower than the used observed velocity. Therefore, an ISW inflow of $1.05 \mathrm{~Sv}$ inflow (which is $15 \%$ lower than the lower estimate limit of 1.2 Sv given by Foldvik et al. [2004]) can result in northward velocities at S2 and S3 similar to those used by Foldvik et al. [2004]. Hence, unless the complex flow structure is accounted for, using only two moorings could lead to an overestimate in the ISW transport. In particular, from the simulated zonal distribution of the depth and timeaveraged plume characteristics along the S section (Figure 8, with the bathymetry shown in Figure 16), it can be seen that in our model the northward component of velocity drops to zero within $30 \mathrm{~km}$ west of S2, while Foldvik et al. [2004]

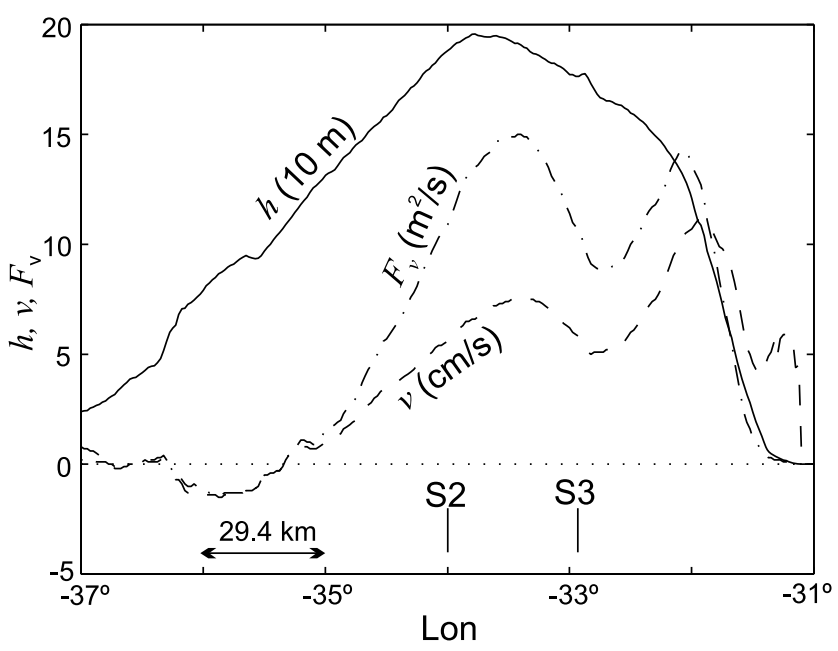

Figure 8. The mean plume depth $h$, northward velocity $v$, and northward transport $F_{v}$ in a meridional cross section passing through mooring S2 at $-74^{\circ} 40^{\prime}$ latitude. 


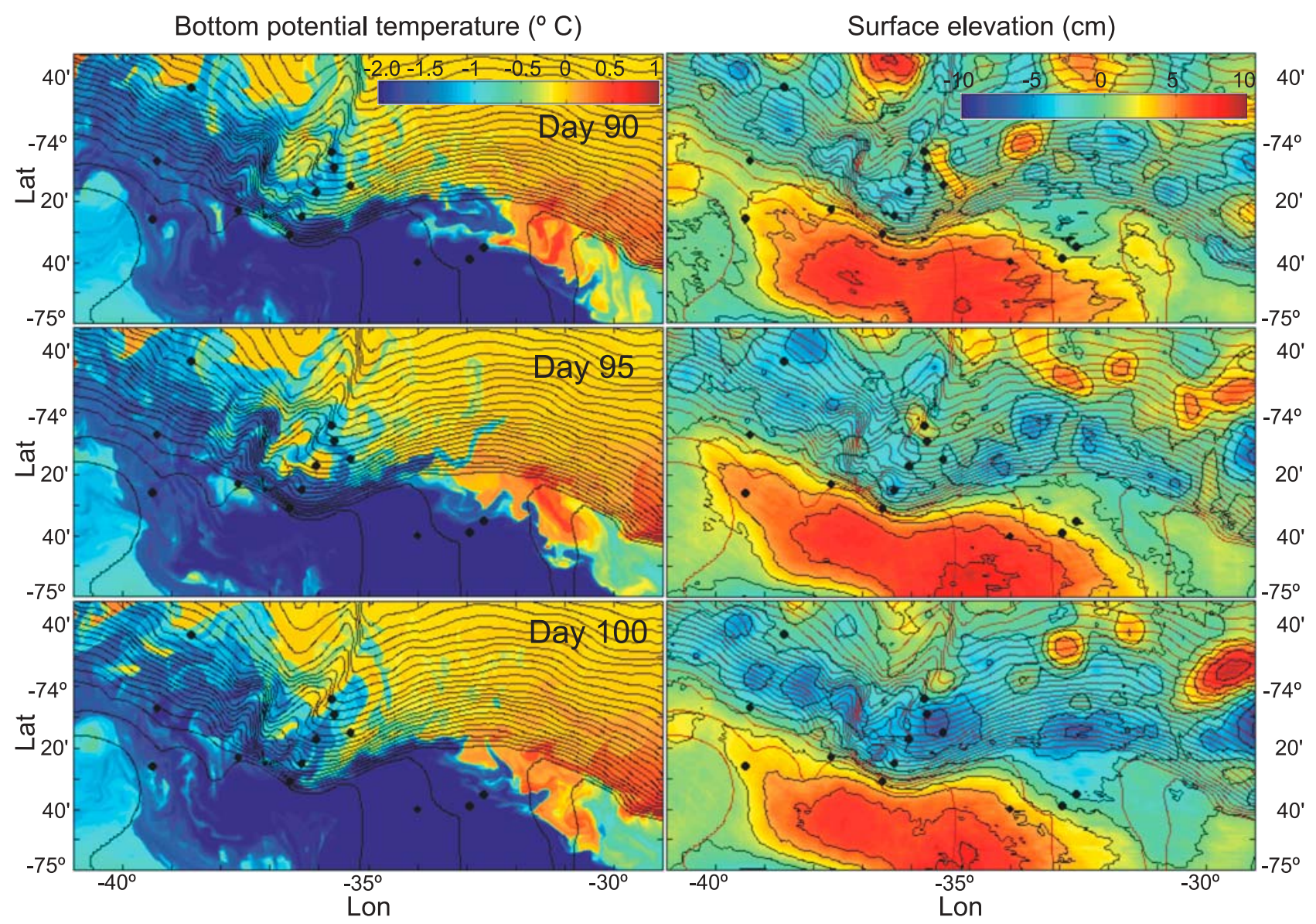

Figure 9. (left) Potential temperature at the bottom. (right) The sea surface height anomaly, with contour lines every $2 \mathrm{~cm}$ on days 90,95 , and 100 .

assumed that the velocity measured at $\mathrm{S} 2$ was constant up to $50 \mathrm{~km}$ westward. There is also a weak reverting flow, as can also be seen in Figure 5, which, while not contributing strongly to the ISW transport, could explain a similar presence of observed reverting flow at mooring FR2.

[21] While the above considerations justify considering $1 \mathrm{~Sv}$ as a reasonable ISW transport estimate, the $0.52 \mathrm{~Sv}$ ISW transport used in run R1 is still only half this. However, the cross-section speed used at the bottom instrument at S2 $\left(6 \mathrm{~cm} \mathrm{~s}^{-1}\right)$ is the 1985 one year mean, which is the maximum one year mean among the three deployment years 1977, 1985 and 1987. The 1987 one year mean was $4.2 \mathrm{~cm} \mathrm{~s}^{-1}$, which is $30 \%$ smaller than in 1985 , therefore accounting for interannual variability could reduce the ISW transport by up to $30 \%$ $(0.3 \mathrm{~Sv})$. The standard instrument errors were $1 \mathrm{~cm} \mathrm{~s}^{-1}$, which for a $100 \mathrm{~km}$ plume width could contribute to a $0.15 \mathrm{~Sv}$ error thereby making ISW transport in the range between 0.5 and $0.7 \mathrm{~Sv}$ realistic for some years.

\section{ISW Plume Dynamics}

\subsection{General Flow Structure}

[22] Here we choose run R2 for a study of instantaneous features of the flow. The plume reaches the western boundary of the model domain on day 25 and by day 40 the flow fully develops. We focus only on the developed phase of the flow: from day 40 through 140 . The average over this period of the velocities, potential temperature, salinity and their standard deviations at the mooring sites are given in Table 3 . We present three consecutive 5 day snapshots of different simulated flow characteristics in the middle of the developed phase, namely on days 90, 95 and 100 in Figures 9-14.

[23] It will clarify our description of the flow if we define some terms. By a subplume we refer to a protuberance extending from the bottom layer of the ISW. We will usually associate subplumes with irregularities of the plume's lateral extension as seen from the bottom potential temperature. By domes we refer to bodies of fluid with local thickness maxima. As such domes also usually undergo relative circular rotational motion we will also call them eddies. It should be noted that subplumes can contain eddies, or even be eddies in their initial phase of formation.

[24] After entering the domain the ISW plume front quickly develops subplumes. The plume first moves northward, then turns west at the continental shelf break and flows alongslope, Figure 9. During the developed phase, the plume flow over the continental shelf does not split into clear domes or eddies as can be seen from the simulated plume depth (Figure 12), even though it develops protuberances at its lateral boundaries that can be due to both barotropic and baroclinic instability. However, when the plume reaches the continental slope it splits into domes that then move along slope. The possible presence of eddies in 


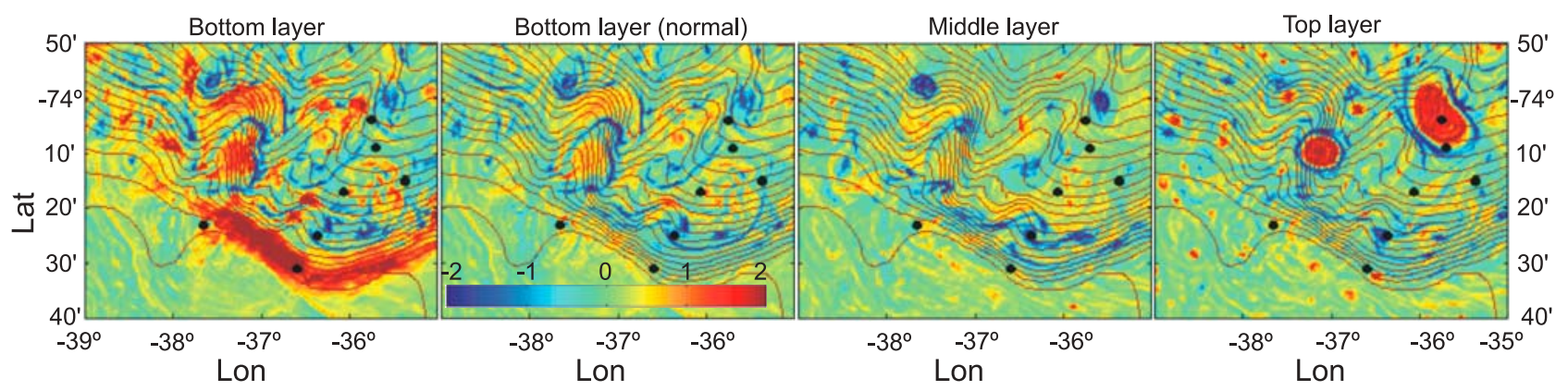

Figure 10. The vertical component of relative vorticity $(\partial v / \partial x-\partial u / \partial y)$ scaled with $10^{-4} \mathrm{~s}^{-1}$ at the bottom, in the middle, and at the surface in the area around the submarine ridges on day 95 . The relative vorticity component normal to the bottom is also shown.

the Filchner overflow was argued by Darelius et al. [2006, 2009] based on mooring data. As was discussed before the reduced gravity of the plume is $g^{\prime}=5 \cdot 10^{-4} \mathrm{~m} \mathrm{~s}^{-2}$. For the typical plume thickness of $h=200 \mathrm{~m}$ this gives the gravityinertia speed of the plume $V=\left(g^{\prime} h\right)^{1 / 2} \approx 0.3 \mathrm{~m} \mathrm{~s}^{-1}$ and the Rossby radius $R=V / f \approx 2.2 \mathrm{~km}$ where $f \approx 1.4 \cdot 10^{-4} \mathrm{~s}^{-1}$ is the Coriolis parameter. Experimental and numerical studies of instability of anomalous buoyancy currents scale the typical distance between eddies near the current's front generated by instability as slightly greater than $L=2 \pi R \approx 14 \mathrm{~km}$ [e.g., Griffiths et al., 1982; Griffiths and Linden, 1982; Condie and Ivey, 1988; Jiang and Garwood, 1995; Swaters, 1998]. Since over the continental shelf the plume length scale is $100 \mathrm{~km}$, instability at the plume edge is not able to break the whole plume into domes, similar to the barotropic instability analysis by Griffiths et al. [1982]. However, when the plume reaches the continental shelf break and becomes as narrow as $30 \mathrm{~km}$ it breaks up into domes. Apart from barotropic instability at the plume edge [Griffiths et al., 1982], two different mechanisms in destabilizing the plume on a continental slope can be identified. Firstly, if the ambient water column is captured and stretched by a reduction in the plume depth, in particular due to geostrophic adjustment and Ekman drainage, then it would acquire cyclonic rotation which is then transferred through the negative pressure to the plume, which in turn would form a dome [Lane-Serff and Baines, 1998]. Superimposition of this cyclonic motion on the anticyclonic geostrophic motion in the dome itself produces a relatively anticyclonic motion in the dome. This mechanism was used by Spall and Price [1998] to describe formation of cyclones in the Denmark Strait. Secondly, baroclinic instability can produce eddies as was predicted by a linear stability analysis by Swaters
[1991]. Numerical studies of this baroclinic instability revealed the development of anticyclones above the domes [Swaters, 1998]. However, solution of a hydrostatic primitive equation model showed cyclonic rotation both above and in baroclinically developed subplumes [Jiang and Garwood, 1995]. Etling et al. [2000] performed laboratory experiments describing generation of eddies due to vortex tube stretching and baroclinic instability and found that in the latter case the cyclonic rotation in the upper layer was much weaker than in the former case. In our simulation water columns at the dome positions are characterized by cyclonic motion where it is distinguishable on the background of a rather complex flow where both cyclonic and anticyclonic motions are present. The cyclonic motion is especially identifiable on day 95 . The vertical component of relative vorticity at the bottom, in the middle and at the top of the water column on day 95 is given in Figure 10. It can be seen that cyclonic motion is not significantly stronger at the upper surface, therefore we presume that they are formed due to baroclinic instability rather than the ambient water vortex tube stretching, which is in contrast to the results of Wang et al. [2009]. The high vertical anticyclonic vorticity at the shelf break is caused by shear from interaction with the slope, since it is hardly present when the vorticity component normal to the bottom is considered. The potential temperature distribution in the $\mathrm{F}$ section presented in Figure 9 shows the nonuniform shape of the plume domes. It can be seen that mixing is greater above the domes' peaks as the negative pressure anomaly in the middle of the cyclone 'sucks' the fluid from above and below into the column.

[25] As one degree longitude is around $30 \mathrm{~km}$ at the latitudes in our simulations, inspection of the close up of the

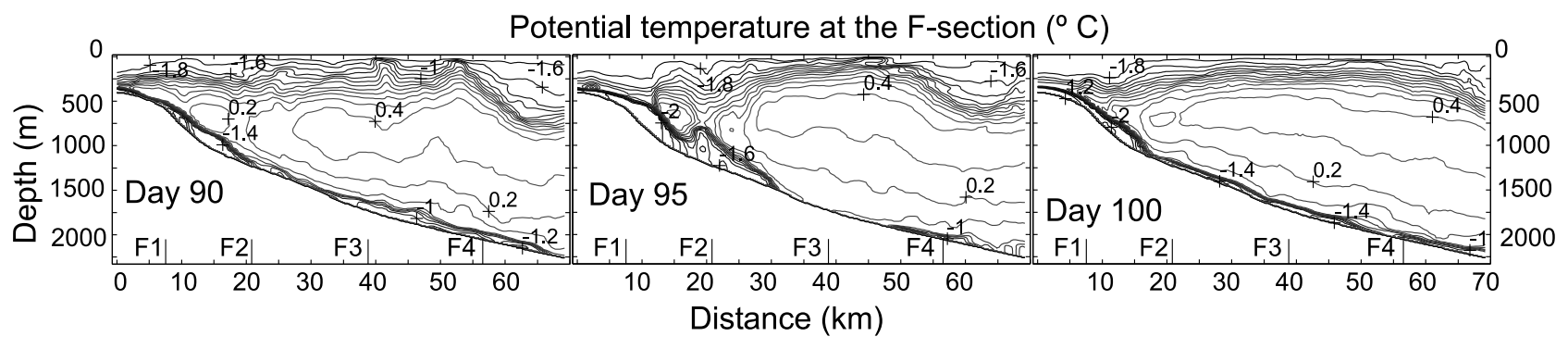

Figure 11. Potential temperature in the F section. 


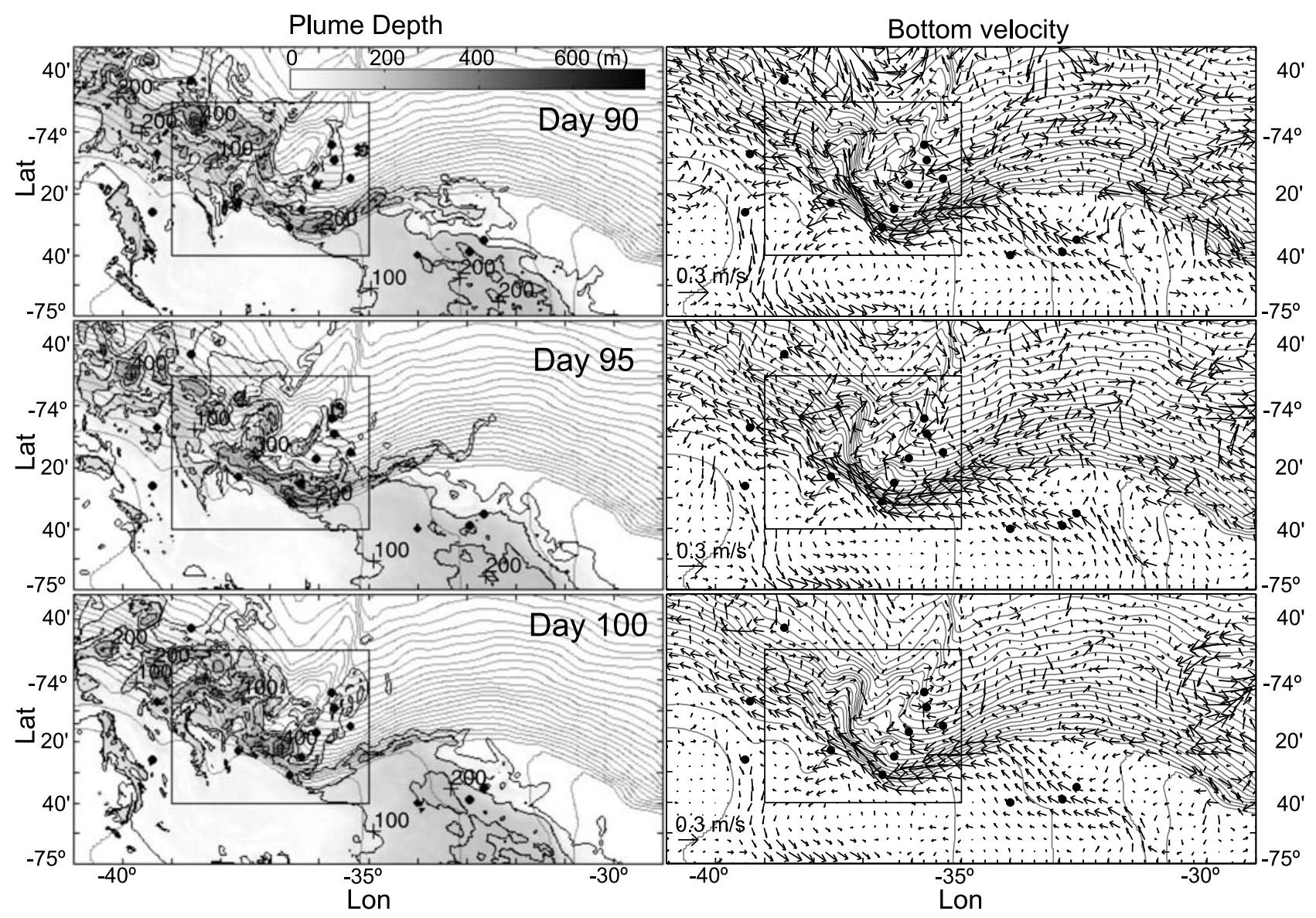

Figure 12. (left) Plume depth and (right) bottom velocity on days 90, 95, and 100. The depth contour lines are every $100 \mathrm{~m}$.

plume thickness in Figure 13 shows that the distance between many neighboring small size domes is $10-20 \mathrm{~km}$. Although domes generated by baroclinic instability can move apart, the baroclinic instability wavelength $L=2 \pi R \approx 14 \mathrm{~km}$ produces a rather good estimate for the typical distance between the domes. The Nof speed $C_{N}=g^{\prime} \alpha / f$, where $\alpha$ is the angle of the slope, describes the speed of along-slope propagation of an anticyclonic eddy under a semi-infinite layer of motionless fluid [Nof, 1983]. Although Mory et al. [1987] found the Nof speed to overestimate their observed speed of isolated eddies by an order of magnitude, later laboratory results by Whitehead et al. [1990], despite a large scatter, showed an order of magnitude correspondence between the Nof speed and the observed speed. Lane-Serff and Baines [1998] in observing eddies produced by ambient vortex tube stretching found the eddy speed to range over more than an order of magnitude depending on the relative effect of the Ekman drainage with a medium value of order $V_{D}=0.5 C_{N}$. Etling et al. [2000] estimated the speed of cyclonic eddies produced by baroclinic instability as $V_{D}=0.4 C_{N}$. Therefore we assume that half of the Nof speed is a good estimate for the alongslope speed of the domes. In our case, the bottom slope at mooring F1 is about $\alpha \approx 0.05$, which yields $V_{D} \approx 9 \mathrm{~cm} \mathrm{~s}^{-1}$. This determines the period of potential temperature oscillation at F1 due to the motion of the domes as the distance between the domes $L \approx 14 \mathrm{~km}$ divided by the dome speed $V_{D}$, which gives 43 hours. Figure 15 shows the simulated potential temperature at different depths of mooring F1 for the considered period 90-100 days. The corresponding observations are given in Figure 5 of Foldvik et al. [2004]. We can see that both Foldvik et al.'s data and our model output oscillate with a large amplitude of order $1^{\circ} \mathrm{C}$ with the period 1-3 days. We associate this oscillation with the motion of the domes and despite a significant variability of the plume characteristics, the estimated $43 \mathrm{~h}$ periodicity is able to capture the main pattern of the potential temperature variability.

[26] Potential temperatures significantly higher than the ISW temperature of $-2.05^{\circ} \mathrm{C}$ at a particular depth show that the plume is not present at that depth. Therefore a significant jump between an ISW temperature and a higher temperature between particular depths implies that the plume top is between these depths. Following this interpretation, according to Figure 15 the ISW has not yet reached F1 on day 90; the plume top is between 10 and 56 mab between days 94 and 95; and between 56 and 207 mab on days 95 and 100 which concurs with Figures 9 and 11. The main difference between the simulation and observation results lie in the difference in the amplitude of the potential temperature oscillation at $10 \mathrm{mab}$. The ambient potential temperature near the bottom at $\mathrm{F} 1$ is around $0.7^{\circ} \mathrm{C}$, and the observed temperature peaks around $0^{\circ} \mathrm{C}$, while the modeled temperature rarely exceeds $-1^{\circ} \mathrm{C}$. In our simulation the low temperature at the bottom is described by the presence of a variable cold bottom layer several tens of meters thick as seen in Figure 13, which is also reflected in the predominant presence of ISW in the 


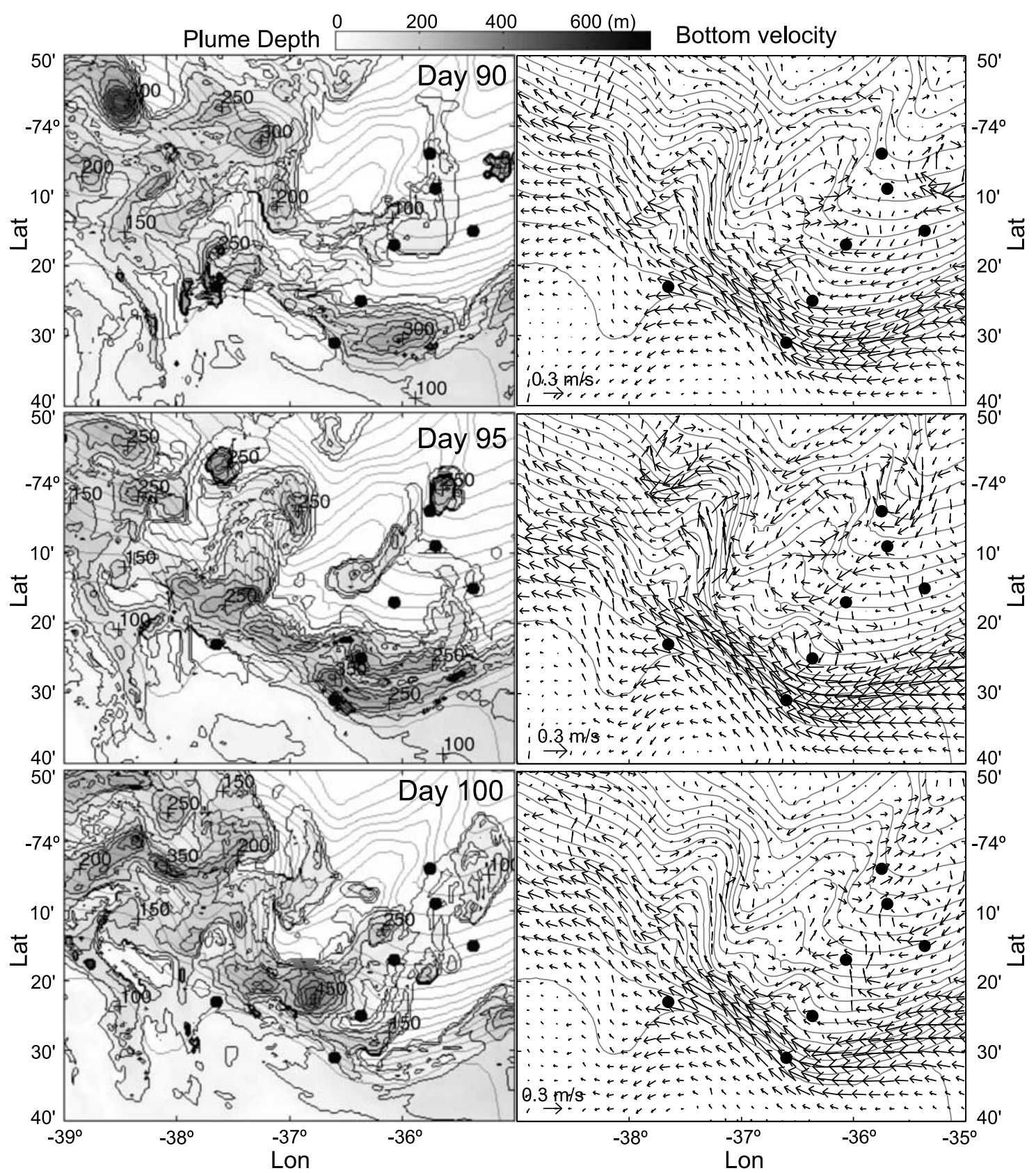

Figure 13. (left) Plume depth and (right) bottom velocity zoomed into the flow area around the ridges on days 90,95 , and 100 . The depth contour lines are every $50 \mathrm{~m}$.

corresponding histogram in Figure 7. We presume that this difference implies that in reality there is a much less steady ISW layer present near the bottom. Generally, decreasing the inflow rate increases potential temperature variability at the bottom as more ISW stays trapped in the eddies. Furthermore, a run that involves eddy formation near the plume entrance through imposing a deeper and narrower plume shape (not shown) improves the correspondence even further as more ISW becomes trapped in the eddies. The potential temperature at mooring F1 also has a small amplitude oscillation of a several hour period, which may be related to the $12 \mathrm{~h}$ inertial period.

[27] One feature of the simulation is the sporadic appearance of strong anticyclones at the surface with speeds exceeding $1 \mathrm{~m} \mathrm{~s}^{-1}$ (Figure 14). Although between days 90 and 100 a surface anticyclone is positioned over a small dome with cyclonic motion at mooring D1, the anticyclone has been over the eastern ridge before day 80 and is not associated with this dome. Although anticyclonic surface motion is not typical for dense overflows, Krauss and Käse [1998] in their simulation of the Denmark Strait overflow found that anticyclones can form in shallow areas. In our model the anticyclones are the consequence of local convergence in the upper layer that leads to a sea surface height anomaly as seen in Figure 9 and deepening of the pycnocline as seen in the F section (Figure 9). A $10 \mathrm{~cm}$ sea surface height anomaly in this case would give rise to a pressure gradient that determines a $1 \mathrm{~m} \mathrm{~s}^{-1}$ barotropic speed with anticyclonic direction 

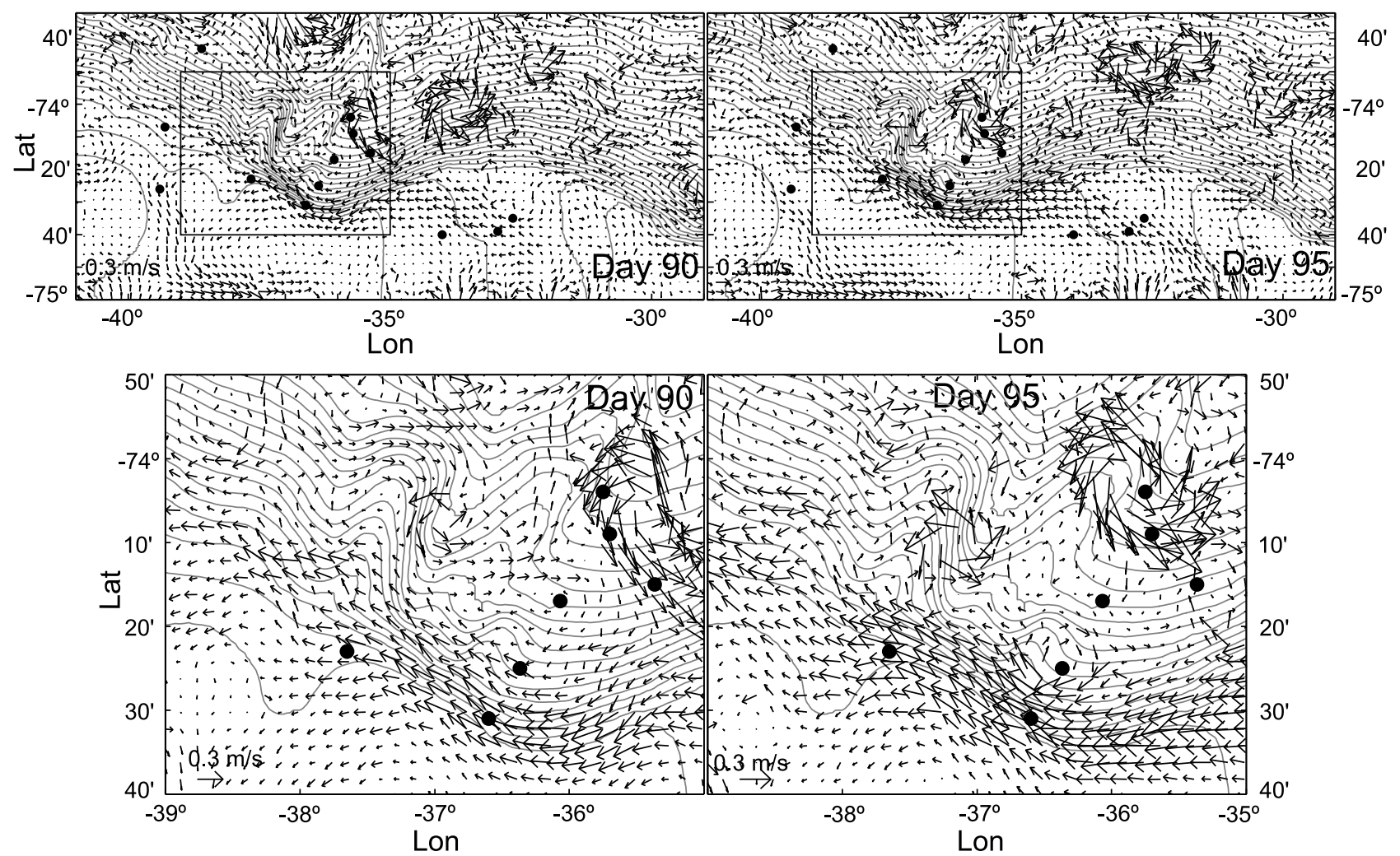

Figure 14. Surface velocities on days 90 and 95 .

and a $7 \mathrm{~km}$ Rossby radius, which describes the scale of the anticyclones within the correct order.

[28] In Figure 16 we also show zonal and meridional cross sections passing through mooring $\mathrm{S} 2$. The zonal cross section compares well with Figure 9 of Foldvik et al. [2004]. The plume clings to the western side of the canyon due to the action of the Coriolis force and, concurring with some observations, its eastern edge is steep. Baines [2005] argued that nonrotating gravity currents on gentle slopes which are in approximate balance between the buoyancy and bottom drag would detrain fluid. A dense particle would leave the plume surface through a mixing event such as a wave breaking away, and then find its equilibrium in the ambient water. As the slope increases, the buoyancy force becomes balanced by vigorous mixing at the upper surface of the plume that drags the local ambient water with the plume describing entrainment. Decreasing of the slope reduces detrainment for the gravity current [e.g., Baines, 2001]. Generally, depending on the buoyancy and shear, mixing over a horizontal density interface occurs through interplay between Kelvin-Helmholz and Hölmböe instability [Strang and Fernando, 2001]. From the meridional cross section of our plume shown in Figure 16 it can be seen that until the plume breaks into eddies, it flows over an almost flat surface, and there is no mixing above the plume. With the adopted mixing coefficient (1), apart from the background mixing, generally there is turbulent mixing predominantly only below the plume surface, even on the continental slope, and therefore the model does not show clear entrainment. At the same time, although waves can be seen on the surface, they do not break away given the considered buoy- ancy and the model resolution, so that detrainment is neither present.

\subsection{Eastern Ridge}

[29] Foldvik et al. [2004] argued that the presence of two prominent ridges may split the plume into at least three branches: one, $\mathrm{FO} 3$, downslope along the eastern ridge, another, FO1, along the shelf break in the direction of mooring $\mathrm{B}$, and the other, $\mathrm{FO} 2$, alongslope in the direction of mooring A diverted downslope from the second branch by the western ridge (Figure 2). Our calculations show that

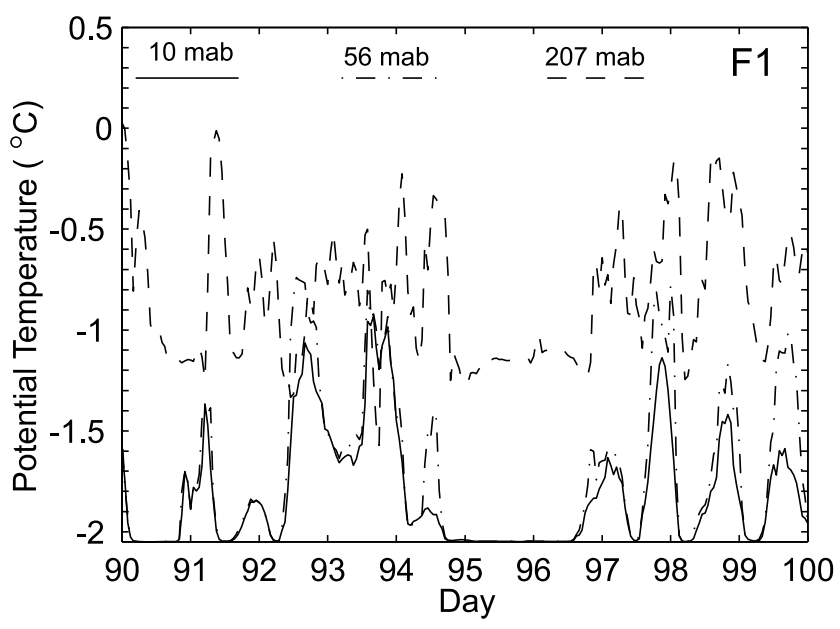

Figure 15. The simulated potential temperature $\left({ }^{\circ} \mathrm{C}\right)$ during the considered 10 days at different depths at mooring F1. 

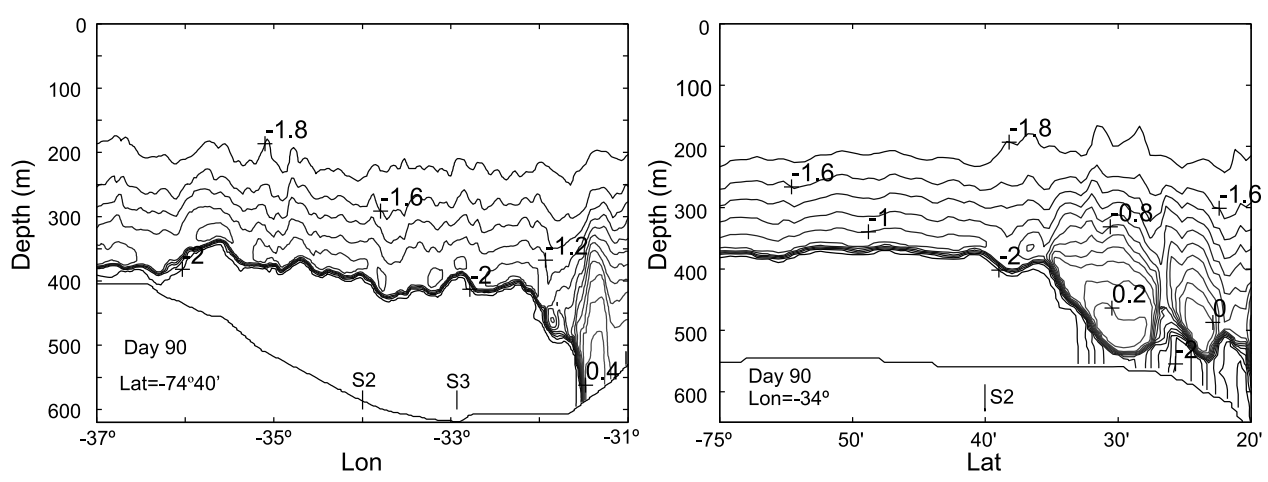

Figure 16. (left) The vertical distribution of the potential temperature $\left({ }^{\circ} \mathrm{C}\right)$ in zonal and (right) meridional cross sections passing through mooring S2 (S section).

since there is a sufficient space between the continental shelf break and the southern end of the eastern ridge, a significant part of the plume is squeezed into this space, while the downslope current along the eastern ridge appears intermittently, determined by the period between which the subplumes run into the ridge. Moreover, the flow along the eastern ridge is rarely in the form of a stable current, but rather in the form of chaotic subplumes of different form that usually become elongated after a period of interaction with the ridge. Some of these subplumes cross over the ridge, while others flow down along the ridge, dissipated during their motion. In particular, Figures 9 and 13 show that on day 90 a subplume has broken away and is moving along the ridge downslope and then encompassing the ridge from the north under the action of the Coriolis force. The subplume is fed by a reverting, anticyclonic flow from the west of the ridge. By day 95 the subplume has split into two parts with the northern part having merged with a dome that has approached mooring D1 which is described by a strong cyclonic motion. The dome then crosses the ridge and runs into the western ridge, while the remaining part merges with the incoming subplume. Generally along the the eastern side of the ridge the ISW is present in different, chaotic shapes constantly supported by injections from the main plume every few days as its subplumes run into the ridge. Although occasionally the water mass overtakes the eastern ridge, since its transport is not significant, the mean plume does not become wider west of the ridge, as shown in Figure 5.

\subsection{Western Ridge}

[30] As the next, western ridge originates closer to the continental shelf break than the eastern ridge, it exerts a more significant influence on the plume shape: generally the plume widens to cover the southern part of the ridge span. This is usually accompanied by the generation of a subplume going north along the ridge and then either turning south over its western side, as can be seen on day 95 , or just flowing over the ridge laterally across its span. These processes are usually accompanied by generation of subplumes breaking away downslope from the northern end of the ridge that move toward mooring $\mathrm{A}$. The subplume encompassing the ridge from the north normally merges with the main plume, which has crossed over the southern part of the ridge. As can be seen on day 115 , water overtaking the eastern ridge contributes to the subplume flowing along the western ridge. Even though the subplume encompassing the western ridge from the north is normally separate from the rest of the plume covering the south of the ridge, we do not see that the western ridge constantly splits the plume into two branches that stay separated. In our model the plume crosses the ridge in a more sporadic manner determined by the incoming plume structure, especially by the position and size of the eddies. Sometimes the plume crosses the ridge through several paths, and sometimes the plume covers the ridge almost completely.

\subsection{Potential Temperature Characteristics at Mooring Locations}

[31] Our results for salinity versus potential temperature for the F section bottom moorings (Figure 17) are generally less scattered with regard to salinity than the observations [Foldvik et al., 2004, Figure 4]. This is probably due to the assumed constant salinity of ISW (34.6 psu) in the model, while the observations show that it is scattered between 34.5 and 34.75 psu. The common feature for moorings F2-F4 measurement data for the prevalent water mass is a transition from ISW to WDW as the mooring depth (and the distance offshore) increases. In our results this trend is also visible, however at F4 the maximum frequency peak shifted toward WDW is much less pronounced than in Foldvik et al.'s data. This signifies a more frequent presence of the plume at F4 than the measurements show. While in Foldvik et al.'s data the ISW is present at all moorings, in our case the lower limits of the potential temperature and salinity gradually increase with the mooring depth. The reason for this, we presume, is the effect of horizontal mixing in our model due to smoothing of numerical noise, as well as the finite numerical accuracy, so that the plume reaches the deeper areas already mixed (decrease of vertical mixing does not significantly improve the situation). The plume reaches the deepest mooring as breakaway subplumes, which, due to their small scale, are more affected by interaction with the ambient, leading to their higher minimum temperature than the shallower moorings F1 and F2 submerged deeper into the main plume.

\subsection{Speed at Mooring Locations F1, F2, D1, and D2}

[32] Generally the simulated speed near the bottom at moorings F1, F2, D1 and D2 (Figure 18 and Table 3) is lower than the measured one. Although the speed is larger for 

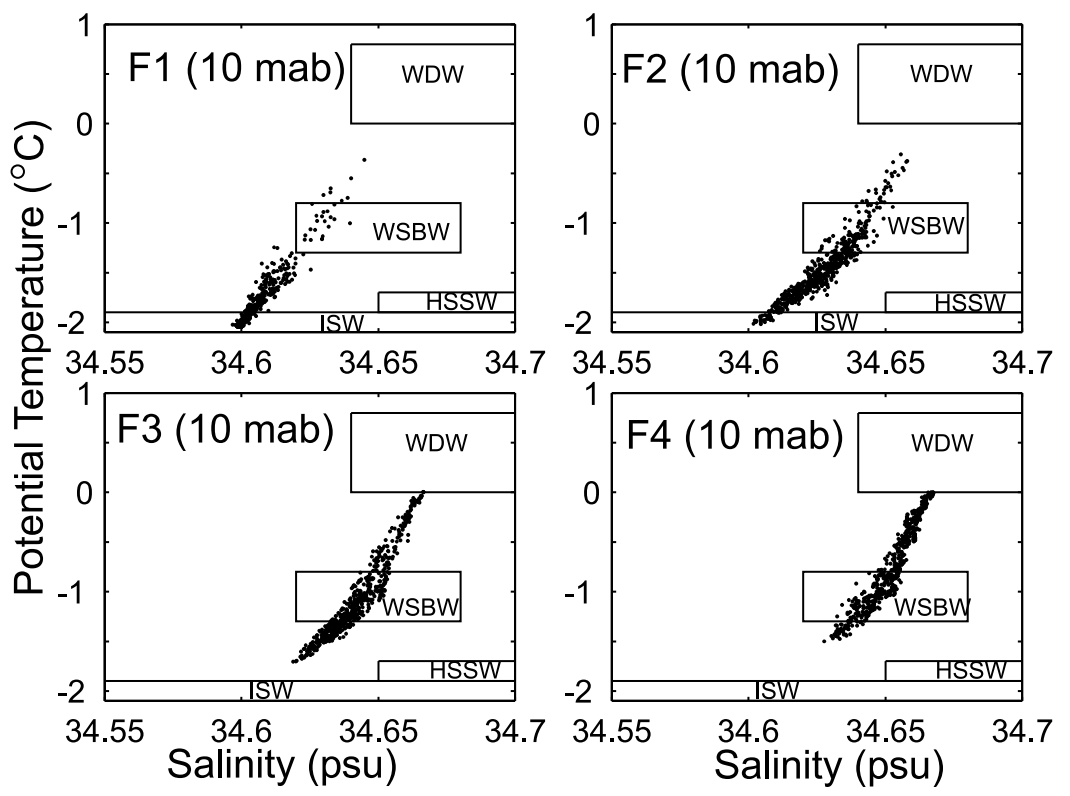

Figure 17. Salinity versus potential temperature scatterplots for the F section bottom moorings using the four hourly data. The water mass definitions are taken from Carmack and Foster [1975], Grosfeld et al. [2001], and Foldvik et al. [2004].

the higher inflow runs R3 and R4, the scattering decreases significantly, which makes the simulated scattergrams in Figure 18 less similar to those given in Figure 12 of Foldvik et al. [2004]. At moorings F1 and F2 there is qualitative agreement between the model and the observations. However, while the measurement data show a clear increase of the speed as the potential temperature decreases at D1 and D2, in our simulations this effect is less significant. Foldvik et al. [2004] interpreted their results by concluding that flow acceleration is caused by flow convergence between $\mathrm{F} 1$ and F2, while it is due to buoyancy-driven descent (helped by thermobaricity and suppressed mixing at supercritical speeds) at D1 and D2. With regard to the latter, our simulation results do not concur with the measurements. Darelius and Wålin [2007] argued that although the flow is fluctuating, it is still quasi-geostrophic due to a small Rossby number for the observed speed of $1 \mathrm{~m} \mathrm{~s}^{-1}$. Our model produces lower speeds, especially at the deepest mooring D1 where the flow structure described by the model (chaotic subplumes) differs from that inferred from the observations (a quasi-geostrophic pulsating current). The difference may arise due to insufficient vertical resolution near the bottom in addition to the higher temperature of the subplumes given by the model. While for a quasi-geostrophic current the speed-potentialtemperature correlation arising from geostrophy is reasonable, in our simulations, where the flow is much more complicated and driven by nongeostrophic interaction with the ridge, such estimates may not hold.

\section{Sensitivity Studies}

\subsection{Smoothed Bottom Topography}

[33] The presence of the prominent ridges plays a role in determining the plume extent. In order to demonstrate the effect of the ridges, we repeat our run R2 with a smoothed bottom topography shown in Figure 19, while all other parameters were kept the same as in our basic case. The water depth for this run was found using the formula

$$
h_{s}(x, y)=\left[1-e^{-\left(x-x_{0}\right)^{2} / \sigma^{2}}\right] h(x, y)+e^{-\left(x-x_{0}\right)^{2} / \sigma^{2}} \bar{h}(x, y),
$$

where $x$ and $y$ are longitude and latitude respectively, $x_{0}=$ $-36.5^{\circ}, \sigma=2^{\circ}, h$ is the original water depth, $\bar{h}(x, y)=$ $\left(1.5^{\circ}\right)^{-1} \int_{x-0.75^{\circ}}^{x+0.7 x^{\circ}} h\left(x_{1}, y\right) d x_{1}$ is the result of averaging $h$ over a 1.5 degree longitude band. Although we were not able to completely smooth out the ridges without depriving the bathymetry of its main features, this formula was found to produce a sufficiently good result. The motion of the plume on the smoothed bottom topography shown in Figure 20a
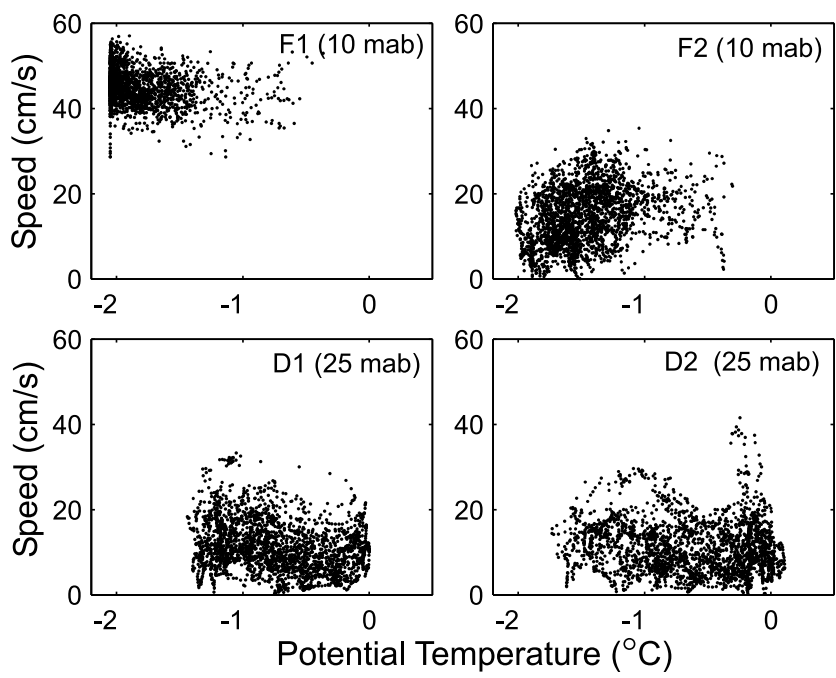

Figure 18. Speed versus potential temperature scatterplots for moorings F1, F2, D1, and D2. Hourly data. 


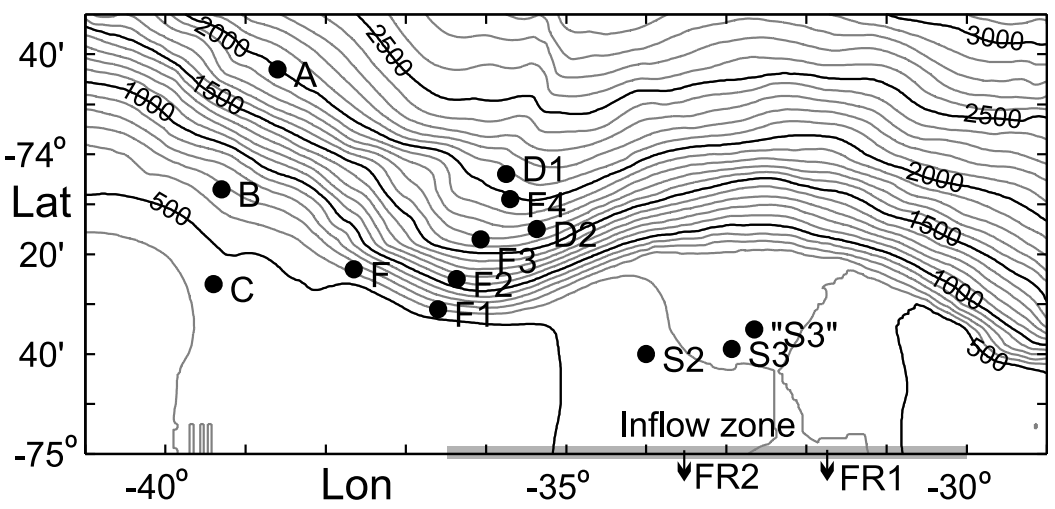

Figure 19. Smoothed bottom topography used to demonstrate the importance of the ridges.

mainly follows the isobaths, and the presence of the ridges affects the plume width, thickness and speed mainly near the ridges. However beyond the ridges the plume characteristics are roughly the same as in run 2 . The WSBW transport for this run denoted as SB in Table 2 is about $15 \%$ smaller than in run $\mathrm{R} 2$, which may be due to the effect of the ridges diverting the flow downslope.

\subsection{Lower Vertical Resolution}

[34] We repeat our run R2 but with a twice grosser vertical resolution (60 sigma layers) to study how sensitive the plume is to vertical resolution. The extent of the plume along the eastern ridge, shown in Figure 20b, visibly reduces and a potential temperature histogram at mooring D1 (not shown) describes a more frequent presence of the ambient water than in the high resolution run R2. Such a loss of accuracy appears because the vertical resolution at D1 is now $30 \mathrm{~m}$ which is significant in comparison to a $100 \mathrm{~m}$ typical depth of subplumes there.

\subsection{Neglect of Thermobaricity}

[35] Killworth [1983] studied simplified plume models and concluded that in order for AABW to reach the ocean floor the dependence of the thermal expansion coefficient

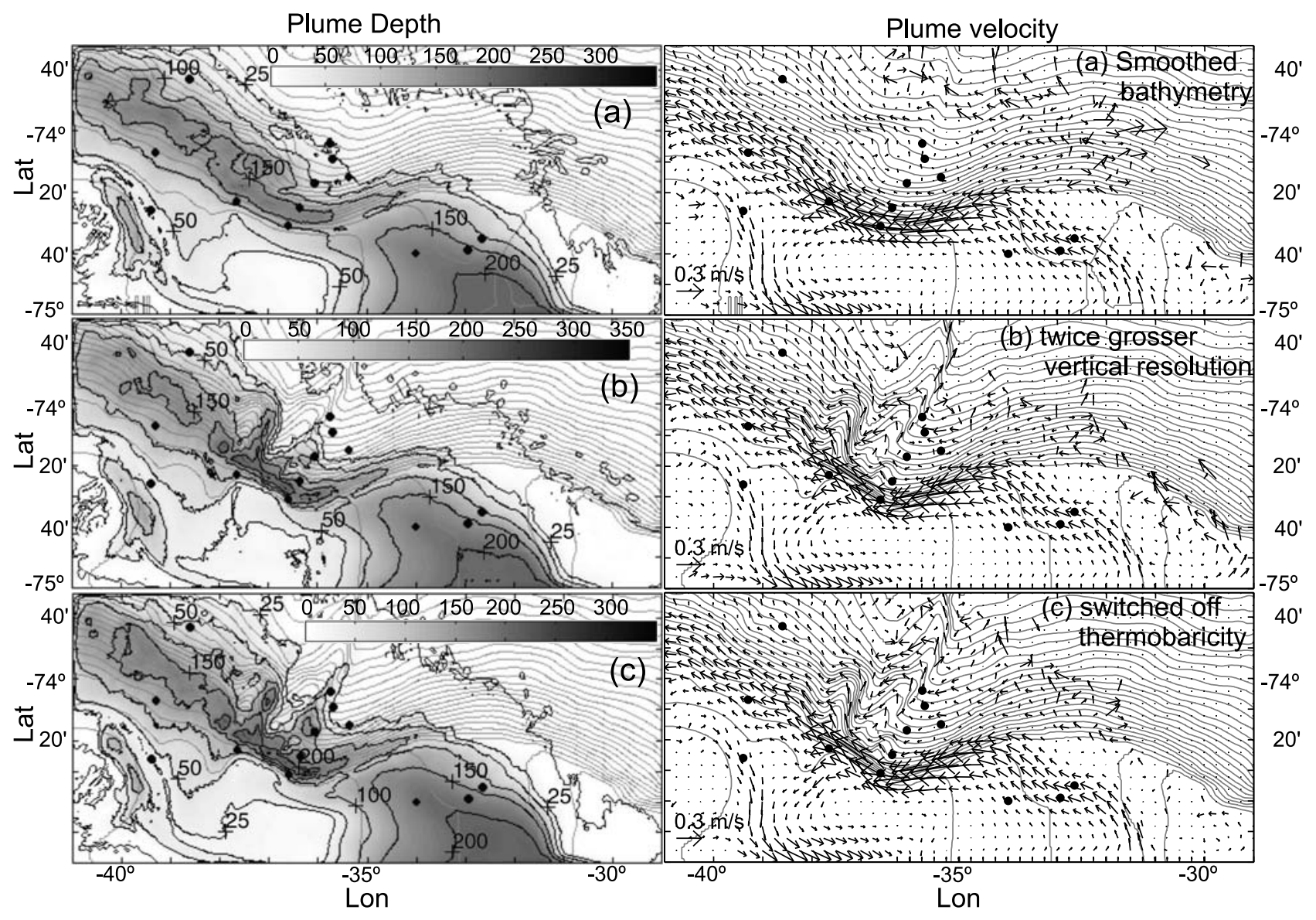

Figure 20. The mean plume depth and velocity for a run (a) on a smoothed bottom topography, (b) with twice grosser vertical resolution, and (c) with thermobaricity switched off. 


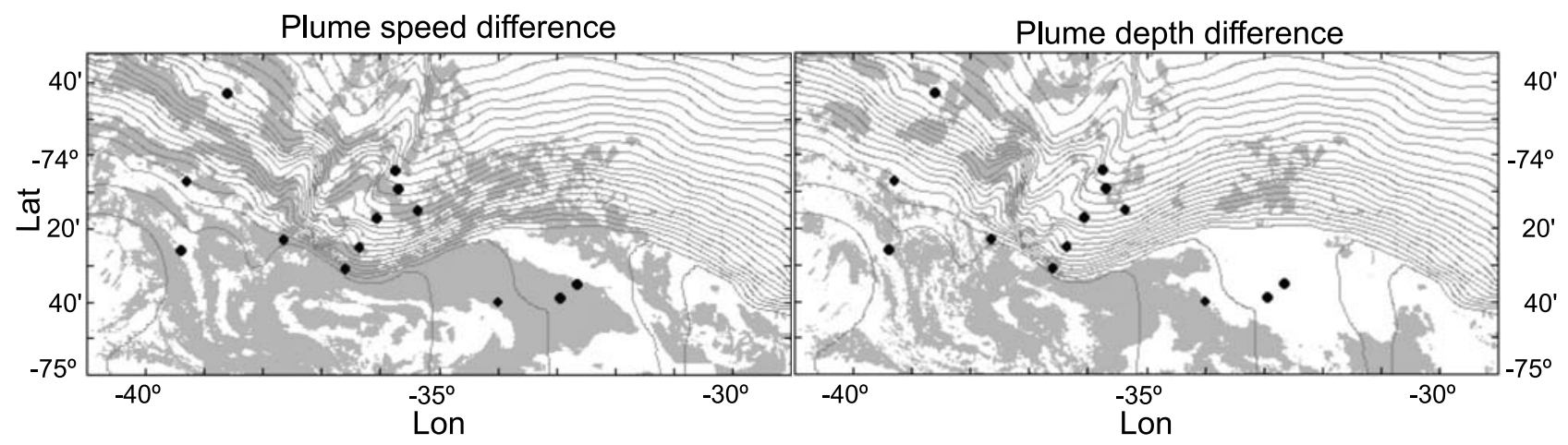

Figure 21. Gray areas show where the plume (left) speed and (right) depth are larger in the standard run R2 than when thermobaricity is switched off.

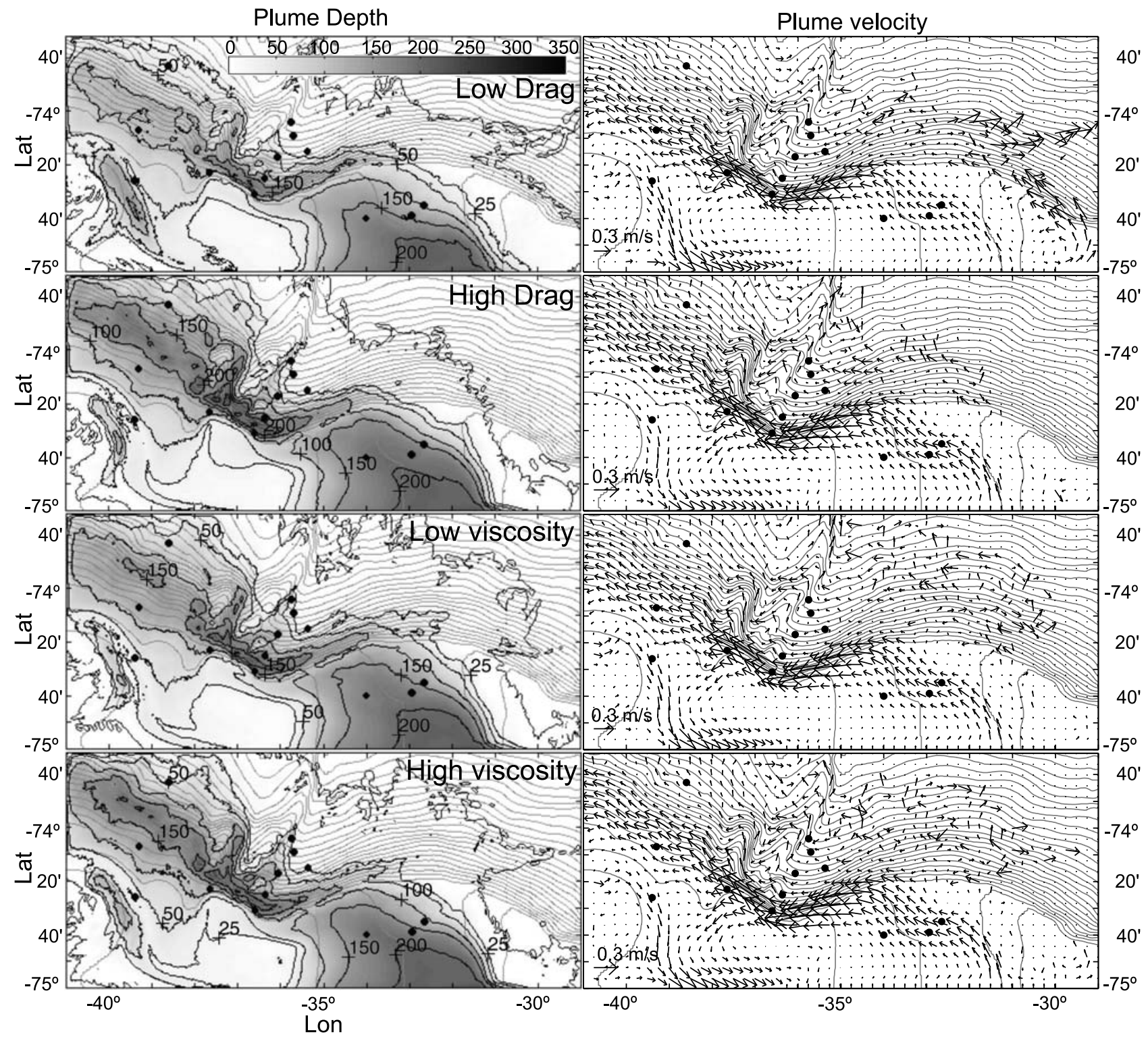

Figure 22. The mean plume depth and velocity vectors for the runs with increased and decreased bottom drag and vertical eddy viscosity. 
on depth should be included. Foldvik et al. [2004] speculated that thermobaric effects could be significant in driving the ISW plume under consideration further downslope along the ridges as the buoyancy difference between the plume and the ambient would increase with depth. POLCOMS allows us to switch off the effect of compression. We used this option to study the importance of thermobaricity while retaining all other parameters as in run $\mathrm{R} 2$. We found that comparing the mean across isobath fluxes to identify the importance of thermobaricity for submarine ridge currents was not meaningful in our model. This is because, as can be seen in Figure 13, the subplumes along the eastern ridge are positioned over sharp changes in the isobath direction, so that from the ridge side the across-isobath direction is effectively perpendicular to the ridge and, hence, the direction of the plume propagation. Therefore, we demonstrate the effect by showing the mean plume depth and velocity vectors (Figure 20c). By comparing these to the R2 results (Figure 5) we see that with thermobaricity switched off the plume becomes thicker along the ridges and therefore its front given by the $25 \mathrm{~m}$ contour line penetrates further downslope. In Figure 21 the gray areas show where the mean speed and depth are larger when thermobaricity is accounted for than when it is switched off. Generally, switching off thermobaricity does not necessarily lead to lower speeds of the plume everywhere, especially along the whole ridge span, so that the effect of thermobaricity on the along-ridge currents in our model is not straightforward. As was discussed earlier, the plume flowing down along the eastern ridge is more diluted than is observed, which (as was pointed out by a reviewer) may lead to a weaker effect of thermobaricity there. However, along the paths of the strongest flow, such as between S2 and "S3", along the continental shelf break, and between A and B the original plume R2 is faster and shallower than the plume with thermobaricity switched off. Such a trend may be described by considering the transport as a product of the gravity-inertia speed and depth to be constant: $Q=h V=g^{1 / 2} h^{3 / 2}=$ const., which gives $h \propto g^{-1 / 3}$ and $V \propto g^{1 / 3}$, so that as the reduced gravity decreases when thermobaricity is not accounted for, the plume depth should increase, while its speed decreases. The WSBW transport across the isobaths referred to by NT in Table 2 is on average just $6 \%$ smaller in comparison with R2, so that in terms of across-isobaths transport the effect of thermobaricity is not significant.

\subsection{Variation of the Bottom Drag and Eddy Viscosity}

[36] Here we test sensitivity of the model results to variation of the bottom drag and eddy viscosity. The quadratic drag law coefficient adopted in the standard run R2 was 0.004 [Mauritzen et al., 2005]. We perform two more runs with drag coefficients of 0.001 and 0.007 , identified here as 'Low Drag' and 'High Drag' respectively. We also study how variation of the eddy viscosity would affect the results. We do this by performing runs with with a fivefold increase and decrease of the eddy viscosity/diffusivity (1) and identify these scenarios as 'Low Viscosity' and 'High Viscosity' cases respectively. As the friction velocity $u_{*}$ entering the eddy viscosity formula is proportional to the square root of the bottom drag, variation of the bottom drag affects the eddy viscosity/diffusivity. In Figure 22 we present the mean depth and velocities of the plumes. As noted above, there is minimal mixing and therefore drag at the upper surface of the plume. While the bottom drag determines the speed of the bottom part of the plume (the higher the drag coefficient, the lower the speed), the eddy viscosity that determines the shear stress within the plume determines the relative speed of the remainder of the plume (the higher the viscosity, the slower the remainder of the plume relative to its bottom speed). It can be seen from Figure 22 that, as could be expected, both increasing the bottom drag or the viscosity leads to deepening and widening of the plume accompanied by its slowing down to conserve mass. Decreasing of these parameters has the opposite effect.

\section{Conclusions}

[37] We have performed high resolution numerical simulations of the Ice Shelf Water (ISW) overflow over the Filchner sill. We have used a hydrostatic, three-dimensional primitive equation ocean model called POLCOMS (Proudman Oceanographic Laboratory Coastal-Ocean Modeling System) with a Richardson number based mixing scheme. Boundary forcing was held constant, and convective and diffusive exchanges of heat, moisture and momentum between the ocean and atmosphere were set to zero in order to focus solely on the internal variability of the flow. Thus, for example, the role of tides as well as the Antarctic coastal current were excluded from our simulations. Our simulations have given insight into the nature and internal variability of the flow, which help to interpret the variability observed at moorings [Foldvik et al., 2004] in terms of the intermittent passage of domes.

[38] Due to a high seasonal and interannual variability we considered four ISW inflow rates of $0.52 \mathrm{~Sv}, 1.05 \mathrm{~Sv}$, $1.56 \mathrm{~Sv}$ and $2.1 \mathrm{~Sv}$. Our simulations showed that runs with $1.56 \mathrm{~Sv}$ and $2.1 \mathrm{~Sv}$ influxes determined a stronger presence of ISW at the mooring locations than observed. The two lower inflow rate scenarios produced better potential temperature histogram fits for different moorings. We presume that since the mooring data were collected at different years, it is not possible to find a best potential temperature histogram fit for a fixed inflow rate, and we chose an intermediate value of $1.05 \mathrm{~Sv}$ for a detailed study of the plume characteristics. While using only one numerical model not accounting for external variable forcing it is not possible to assert that the $0.5-1 \mathrm{~Sv}$ range is more realistic than the $1.6 \pm 0.5 \mathrm{~Sv}$ found by Foldvik et al. [2004], we argue that the sparseness of data used by Foldvik et al. [2004] may have been responsible for an overestimate of the ISW inflow rate as our model with a $1.05 \mathrm{~Sv}$ ISW transport produces on average higher velocities at the mooring positions. Moreover, accounting for interannual variability could further reduce the ISW transport estimate down to the $0.5-0.7 \mathrm{~Sv}$ range.

[39] Our simulations show that the plume of ISW propagates along the continental slope in the form of subplumes and domes. The ISW first moves north over the continental shelf until it reaches its break where it breaks into eddies and subplumes, and then turns west and moves along it. The first barrier on its way is the eastern ridge which is situated slightly away from the continental shelf break, so that part of the plume carries on south of it. Offshore subplumes 
however run into the ridge and then propagate along its eastern side downslope in a chaotic manner. During interaction with the ridge such subplumes may elongate along it, or cross the ridge in several places. While our model describes sporadic subplumes moving along the eastern side of the ridge, it is not able to reproduce a pulsating geostrophic current interpreted from observations [Foldvik et al., 2004; Darelius and Wählin, 2007], and since the simulated speed (Table 3) is up to five times smaller than the observed one, we attribute this inconsistency only to our model's performance discussed below. On average, as there is enough space south of the ridge for the plume to propagate along slope, the plume widens only before the ridge. The effect of the next, western ridge is more significant as it extends almost up to the continental shelf break and obstructs the ISW flow to a higher degree. In reaching the western ridge the plume widens. In particular, while part of it moves on along the shelf break, another part is diverted north, flows along the ridge and then encompasses the ridge from the north. These two currents then join again after crossing the ridge. At the same time the plume overtakes the ridge over different segments of its span in a way which depends on the structure of the incoming plume. The plume can also cover the ridge completely. West of the ridge the plume moves mainly along the isobaths until it leaves the domain at $-41^{\circ}$ longitude with a typical potential temperature of $-1.5^{\circ} \mathrm{C}$ in contrast to its initial potential temperature of $-2.05^{\circ} \mathrm{C}$.

[40] The observations by Foldvik et al. [2004] show a high degree of temporal variability at mooring F1. Our simulation show a similar picture, albeit with a smaller amplitude, even though no external variability was included. From the temporal evolution of the potential temperature at F1 we identify the typical period of large amplitude oscillations as 1-3 days. We argue that this period is determined by the frequency of passing domes, with the estimate derived by considering the domes to move with half of the Nof speed and being an instability wavelength ( $2 \pi$ Rossby radius) apart.

[41] Our potential temperature histograms at the mooring sites generally describe a picture qualitatively similar to the observations. However, the model produces warmer ISW at deeper moorings F3, F4 and D1 situated away from the main plume where ISW reached the moorings in the form of breakaway subplumes. As variation of vertical mixing in the model does not improve the situation (not shown), we speculate that generally the model produces too strong numerical horizontal mixing. A too strong horizontal mixing would have its strongest influence on small break away subplumes surrounded by the ambient water, and therefore its effect would be especially significant for the deep moorings. As such mixing produces warmer ISW, this could determine a lower speed of subplumes flowing down the ridges, as well as reduce the effect of thermobaricity due to a smaller density anomaly. While it can be assumed that the temperature at mooring $\mathrm{C}$ on the continental shelf is affected by HSSW formation, our calculations show that even with no HSSW accounted for, the plume can reach the mooring with the resulting potential temperature histogram being realistic. Our simulation also shows that mooring $\mathrm{A}$ is reached by the plume in a well mixed form and corresponds to the measurements of Foldvik et al. [2004].

[42] One major discrepancy between the model and the observations lies in the speed characteristics at moorings D1 and D2. Generally the model produces a slower motion of the plume; while the plume speed can be increased by increasing the inflow rate, this would worsen the histogram fit. The observations show a high potential temperature versus speed correlation at moorings D1 and D2, and a low correlation at F1 and F2. This led Foldvik et al. [2004] to conclude that acceleration of the downslope current along the eastern ridge is determined by buoyancy, while acceleration of the flow along the continental break south of it (at F1 and F2) is due to convergence. Although our model does produce a qualitative agreement with regard to F1 and F2, the simulated speedpotential-temperature correlation is hardly reproduced at D1 and D2. The reason for this discrepancy is still unclear. At D1 the discrepancy is determined by the difference in the downslope current characteristics produced by the model (chaotic subplumes) in comparison to the observations (a pulsating geostrophic current). While in the latter case a speed-potential-temperature correlation can be expected to hold due to the geostrophic balance in this steady flow [Darelius and Wälin, 2007], the complexity of the flow in our model may render such estimates inadequate due a nontrivial interaction with the ridge. A possible reason for our model not producing a pulsating geostrophic current is that, as discussed above, the model produces too much horizontal numerical mixing. The strong horizontal mixing will result in warmer and less dense small-scale subplumes in which the geostrophic balance is less dominant. Lower model resolution at greater depths may also play a role.

[43] Our sensitivity studies have shown that the presence of the ridges is an important factor determining the plume dynamics and lateral extent around the ridges. Away from the ridges their influence is less pronounced. For the considered run $\mathrm{R} 2$, thermobaricity makes the plume faster and thinner, but its quantitative effect is not significant. In particular, the across isobath WSBW transport increases only by $6 \%$ on average with thermobaricity. The bottom drag and vertical mixing variation have a similar effect: when they increase, the plume slows down and to conserve its volume flux, thickens and widens; and vice versa when they decrease.

[44] Our study, by excluding external forcing, has focused on the role of internal variability in describing the Filchner overflow. While this has led to many insights concerning the flow, a more realistic simulation must include external forcing, in particular, seasonal variability of the ISW inflow, which as implied by our simulations should have a significant effect on the comparison between observations and model simulations. Other factors that should be explored are the role of tides, the Weddell Sea Gyre/Antarctic coastal current, and HSSW formation. It is possible that, by including such sources of external variability, the remaining discrepancies between the observations and model simulations may be removed or reduced.

[45] Acknowledgments. Comments of the anonymous reviewers helped us improve the manuscript substantially. D. L. Feltham acknowledges financial support made possible through the award of a Prize by the Leverhulme Trust. We thank Keith Nicholls, Keith Makinson, and Paul Holland for useful discussions.

\section{References}

Baines, P. G. (2001), Mixing in flows down gentle slopes into stratified environment, J. Fluid Mech., 443, 237-270, doi:10.1017/ S0022112001005250. 
Baines, P. G. (2005), Mixing regimes for the flow of dense fluid down slopes into stratified environment, J. Fluid Mech., 538, 245-267, doi:10.1017/S0022112005005434.

Carmack, E., and T. D. Foster (1975), Circulation and distribution of oceanographic properties near the Filchner Ice Shelf, Deep Sea Res., 22(2), 77-90, doi:10.1016/0011-7471(75)90097-2.

Condie, S. A., and G. N. Ivey (1988), Convectively driven coastal currents in a rotating basin, J. Mar. Res., 46, 473-494.

Darelius, E., and A. Wåhlin (2007), Downward flow of dense water leaning on a submarine ridge, Deep Sea Res. Part I, 54(7), 1173-1188, doi:10.1016/j.dsr.2007.04.007.

Darelius, E., S. Østerhus, and T. Gammelsrød (2006), Variability of the Filchner overflow, in Forum for Research into Ice Shelf Processes, edited by L. H. Smedsrud, Rep. 17, pp. 7-13, Br. Antarct. Surv., Cambridge, U. K.

Darelius, E., L. H. Smedsrud, S. Østerhus, A. Foldvik, and T. Gammelsrød (2009), Structure and variability of the Filchner overflow plume, Tellus Ser. $A, 61,446-464$, doi:10.1111/j.1600-0870.2009.00391.x.

Deacon, G. E. R. (1937), The hydrology of the Southern Ocean, Discovery Rep., 15, 3-122.

Deleersnijder, E., and P. Luyten (1994), On the practical advantages of the quasi-equilibrium version of the Mellor and Yamada level 2.5 turbulence closure applied to numerical modeling, Appl. Math. Modell., 18(5), 281287, doi:10.1016/0307-904X(94)90336-0.

Etling, D., F. Gelhardt, U. Schrader, F. Brennecke, G. Kühn, G. Chabert d'Hieres, and H. Didelle (2000), Experiments with density currents on a sloping bottom in a rotating fliud, Dyn. Atmos. Oceans, 31(1-4), 139-164, doi:10.1016/S0377-0265(99)00031-7.

Foldvik, A., and T. Gammelsrød (1988), Notes on Southern Ocean hydrography, sea-ice and bottom water formation, Palaeogeogr. Palaeoclimatol. Palaeoecol., 67(1-2), 3-17, doi:10.1016/0031-0182(88)90119-8.

Foldvik, A., T. Gammelsrød, and T. Tørresen (1985a), Physical oceanography studies in the Weddell Sea during the Norwegian Antarctic Research Expedition 1967/1977, Polar Res., 3(2), 195-207, doi:10.1111/j.17518369.

Foldvik, A., T. Gammelsrød, and T. Tørresen (1985b), Hydrographic observations from the Weddell Sea during the Norwegian Antarctic Research Expedition 1978/79, Polar Res., 3(2), 177-193, doi:10.1111/j.1751-8369.1985.tb0056.x.

Foldvik, A., T. Gammelsrød, E. Nygaard, and S. Østerhus (2001), Current measurements near Ronne Ice Shelf: Implications for circulation and melting, J. Geophys. Res., 106(C3), 4463-4477.

Foldvik, A., T. Gammelsrød, S. Østerhus, E. Fahrbach, G. Rohardt, M. Schröder, K. W. Nicholls, L. Padman, and R. A. Woodgate (2004), Ice shelf water overflow and bottom water formation in the southern Weddell Sea, J. Geophys. Res., 109, C02015, doi:10.1029/ 2003JC002008.

Foster, T. D., and E. C. Carmack (1976), Frontal zone mixing and Antarctic Bottom Water formation in the southern Weddell Sea, Deep Sea Res., 23(4), 301-317, doi:10.1016/0011-7471(76)90872-X.

Gill, A. E. (1973), Circulation and bottom water production in the Weddell Sea, Deep Sea Res., 20(2), 111-140, doi:10.1016/0011-7471(73)90048-X.

Gordon, A. L. (1998), Western Weddell Sea thermohaline stratification, in Ocean, Ice and Atmosphere: Interatcion at the Antarctic Continental Margin, Antarct. Res. Ser., vol. 75, edited by S. S. Jacobs and R. F. Weiss, pp. 215-240, AGU, Washington, D. C.

Griffiths, R. W., and P. F. Linden (1982), Laboratory experiments on fronts. Part I: Density-driven boundary currents, Geophys. Astrophys. Fluid Dyn., 19(3-4), 159-187, doi:10.1080/03091928208208954.

Griffiths, R. W., P. D. Killworth, and M. E. Stern (1982), Ageostrophic instability of ocean currents, J. Fluid Mech., 117, 343-377, doi:10.1017/ S0022112082001669.

Grosfeld, K., M. Schröder, E. Fahrbach, R. Gerdes, and A. Makensen (2001), How iceberg calving and grounding change the circulation and hydrography in the Filchner Ice Shelf-Ocean System, J. Geophys. Res., 106(C10), 9039-9055.

Holt, J. T., and I. D. James (1999), A simulation of the southern North Sea in comparison with measurements from the North Sea Project. Part 1: Temperature, Cont. Shelf Res., 19(8), 1087-1112, doi:10.1016/S02784343(99)00015-1.

Holt, J. T., and I. D. James (2001), An $s$ coordinate density evolving model of the northwest European continental shelf: 1. Model description and density structure, J. Geophys. Res., 106(C7), 14,015-14,034.

Holt, J., and R. Proctor (2008), The seasonal circulation and volume transport on the northwest European continental shelf: A fine-resolution model study, J. Geophys. Res., 113, C06021, doi:10.1029/2006JC004034.
James, I. D. (1996), Advection schemes for shelf sea models, J. Mar. Syst., 8(3-4), 237-254, doi:10.1016/0924-7963(96)00008-5.

Jiang, L., and R. W. Garwood Jr. (1995), A numerical study of threedimensional dense plumes on a Southern Ocean continental slope, J. Geophys. Res., 100(C9), 18,471-18,488.

Killworth, P. D. (1983), Mixing on the Weddell Sea continental slope, Deep Sea Res. Part I, 24, 427-448.

Killworth, P. D., D. Stainforth, D. J. Webb, and S. M. Paterson (1991), The development of a free-surface Bryan-Cox-Semtner ocean model, J. Phys. Oceanogr., 21(9), 1333-1348, doi:0.1175/1520-0485(1991)021< 333: TDOAFS $>2.0 . \mathrm{CO} ; 2$

Krauss, W., and R. Käse (1998), Eddy formation in Denmark Strait overflow, J. Geophys. Res., 103(C8), 15,815-15,970.

Lane-Serff, G. F., and P. G. Baines (1998), Eddy formation by dense flows on slopes in a rotating fluid, J. Fluid Mech., 363, 229-252.

Makinson, K., and K. W. Nicholls (1999), Modeling tidal currents beneath Filchner-Ronne Ice Shelf and on the adjacent continental shelf: Their effect on mixing and transport, J. Geophys. Res., 104(C6), 13,44913,465 .

Matsumura, Y., and H. Hasumi (2008), A non-hydrostatic ocean model with a scalable multigrid Poisson solver, Ocean Modeling, 24, 15-28, doi:10.1016/j.ocemod.2008.05.001.

Mauritzen, C., J. Price, T. Sanford, and D. Torres (2005), Circulation and mixing in the Faroese Channels, Deep Sea Res. Part I, 52(6), 883-913, doi:10.1016/j.dsr.2004.11.018.

Mellor, G. L. (1991), An equation of state for numerical models of oceans and estuaries, J. Atmos. Oceanic Technol., 8(4), 601-611, doi:10.1175/ 1520-0426(1991)008<0609:AEOSFN $>2.0 . \mathrm{CO} ; 2$.

Middleton, J. H., T. D. Foster, and A. Foldvik (1982), Low-frequency currents and continental shelf waves in the southern Weddell Sea, J. Phys. Oceanogr., 12(7), 618-634, doi:010.1175/1520-0485(1982)012< 0618:LFCACS $>2.0 . \mathrm{CO} ; 2$

Mory, R., M. Stern, and R. Griffiths (1987), Coherent baroclinic eddies on a sloping bottom, J. Fluid Mech., 183, 45-62, doi:10.1017/ S0022112087002519.

Nicholls, K. W., and S. Østerhus (2004), Interannual veriability and ventilation timescales in the ocean cavity beneath Filchner-Ronne Ice Shelf, Antarctica, J. Geophys. Res., 109, C04014, doi:10.1029/2003JC002149.

Nicholls, K. W., S. Østerhus, K. Makinson, and M. R. Johnson (2001), Oceanographic conditions south of Berkner Island, beneath FilchnerRonne Ice Shelf, Antarctica, J. Geophys. Res., 106(C6), 11,481-11,492.

Nof, D. (1983), The translation of isolated cold eddies on a sloping bottom, Deep Sea Res. Part I, 30(2), 171-182.

Renfrew, I. A., J. C. King, and T. Markus (2002), Coastal polynyas in the southern Weddell Sea: Variability of the surface energy budget, J. Geophys. Res., 107(C6), 3063, doi:10.1029/2000JC000720.

Spall, M., and J. Price (1998), Mesoscale variability in Denmark Strait: The PV outflow hypothesis, J. Phys. Oceanogr., 28(8), 1598-1623, doi:10.1175/1520-0485(1998)028<1598:MVIDST >2.0.CO;2.

Strang, E. J., and H. J. S. Fernando (2001), Entrainment and mixing in stratified shear flows, J. Fluid Mech., 428, 349-386.

Swaters, G. E. (1991), On the baroclinic instability of cold-core coupled density fronts on a sloping continental shelf, J. Fluid Mech., 224, $361-$ 382, doi: $10.1017 /$ S0022112091001799.

Swaters, G. E. (1998), Numerical simulations of the baroclinic dynamics of density-driven coupled fronts and eddies on a sloping bottom, J. Geophys. Res., 103(C2), 2945-2961.

Wang, Q., S. Danilov, and J. Schröter (2009), Bottom water formation in southern Weddell Sea and the indluence of submarine ridges: Idealized simulations, Ocean Modell., 28, 50-59, doi:10.1016/j.ocemod. 2008.08.003.

Whitehead, J., M. Stern, G. Flierl, and B. Klinger (1990), Experimental observations of baroclinic eddies on a sloping bottom, J. Geophys. Res., 95(C6), 9585-9610.

Wilchinsky, A. V., and D. L. Feltham (2008), Generation of a buoyancydriven coastal current by an Antarctic polynya, J. Phys. Oceanogr., 38(5), 1011-1032, doi:10.1175/2007JPO3831.1.

D. L. Feltham and A. V. Wilchinsky, Centre for Polar Observation and Modeling, National Centre for Earth Observation, University College London, Gower St., London WC1E 6BT, UK. (dlf@cpom.ucl.ac.uk; aw@cpom.ucl.ac.uk) 